\title{
Analytical Approach to Circulating Current Mitigation in Hexagram Converter-Based Grid-Connected Photovoltaic Systems Using Multiwinding Coupled Inductors
}

\author{
Abdullrahman A. Al-Shamma'a $\mathbb{D D}^{1,2}$ Abdullah M. Noman ${ }^{\mathbb{D}},{ }^{1,2}$ Khaled E. Addoweesh, \\ Ayman A. Alabduljabbar, ${ }^{3}$ and A. I. Alolah ${ }^{1}$ \\ ${ }^{1}$ Department of Electrical Engineering, College of Engineering, King Saud University, Riyadh 11421, Saudi Arabia \\ ${ }^{2}$ Department of Mechatronics Engineering, College of Engineering, Taiz University, Taiz, Yemen \\ ${ }^{3}$ King Abdulaziz City for Science and Technology (KACST), P.O. Box 6086, Riyadh 11442, Saudi Arabia \\ Correspondence should be addressed to Abdullrahman A. Al-Shamma’a; ashammaa@ksu.edu.sa
}

Received 31 December 2017; Accepted 2 April 2018; Published 7 May 2018

Academic Editor: Francesco Riganti-Fulginei

Copyright () 2018 Abdullrahman A. Al-Shamma'a et al. This is an open access article distributed under the Creative Commons Attribution License, which permits unrestricted use, distribution, and reproduction in any medium, provided the original work is properly cited.

\begin{abstract}
The hexagram multilevel converter (HMC) is composed of six conventional two-level voltage source converters (VSCs), where each VSC module is connected to a string of PV arrays. The VSC modules are connected through inductors, which are essential to minimize the circulating current. Selecting inductors with suitable inductance is no simple process, where the inductance value should be large to minimize the circulating current as well as small to reduce an extra voltage drop. This paper analyzes the utilization of a multiwinding (e.g., two, three, and six windings) coupled inductor to interconnect the six VSC modules instead of six single inductors, to minimize the circulating current inside the HMC. Then, a theoretical relationship between the total impedance to the circulating current, the number of coupled inductor windings, and the magnetizing inductance is derived. Owing to the coupled inductors, the impedance on the circulating current path is a multiple of six times the magnetizing inductance, whereas the terminal voltage is slightly affected by the leakage inductance. The HMC is controlled to work under variable solar radiation, providing active power to the grid. Additional functions such as DSTATCOM, during daytime, are also demonstrated. The controller performance is found to be satisfactory for both active and reactive power supplies.
\end{abstract}

\section{Introduction}

Recently, photovoltaic (PV) energy systems have gained more attention as distributed generation units, as they offer low cost of generation closer to that of conventional plants, as well as less maintenance and no grid noise $[1,2]$. Moreover, PV systems can solve multiple typical problems present in conventional AC power systems. However, PV systems present frequency and voltage fluctuations when islanding operation occurs. Therefore, PV plants should be integrated with the power system in order to maintain the overall frequency and voltage at a stable condition. Several studies suggest interconnection methods of PV systems to the grid through voltage source converters (VSCs), because they provide versatile functions enhancing capabilities of the system
[3-5]. The main purpose of the VSC is to connect the PV plant to the grid while guaranteeing power quality (PQ) standards. However, the high-frequency switching of VSCs introduces additional harmonic components to the system, hence creating PQ problems if not implemented accurately [6].

Most of the available VSCs for PV systems are traditional two-level three-phase VSCs with low power capacity [7]. In the literature, researchers have suggested numerous multilevel topologies for grid-connected PV plants [8-10]. Multilevel VSCs are considered more attractive than traditional two-level VSCs, as they improve the output voltage quality and reduce electromagnetic interference, voltage stress on IGBTs, and common-mode voltage. Moreover, multilevel VSCs operate at a low switching frequency and hence increase system efficiency [10]. Consequently, multilevel 

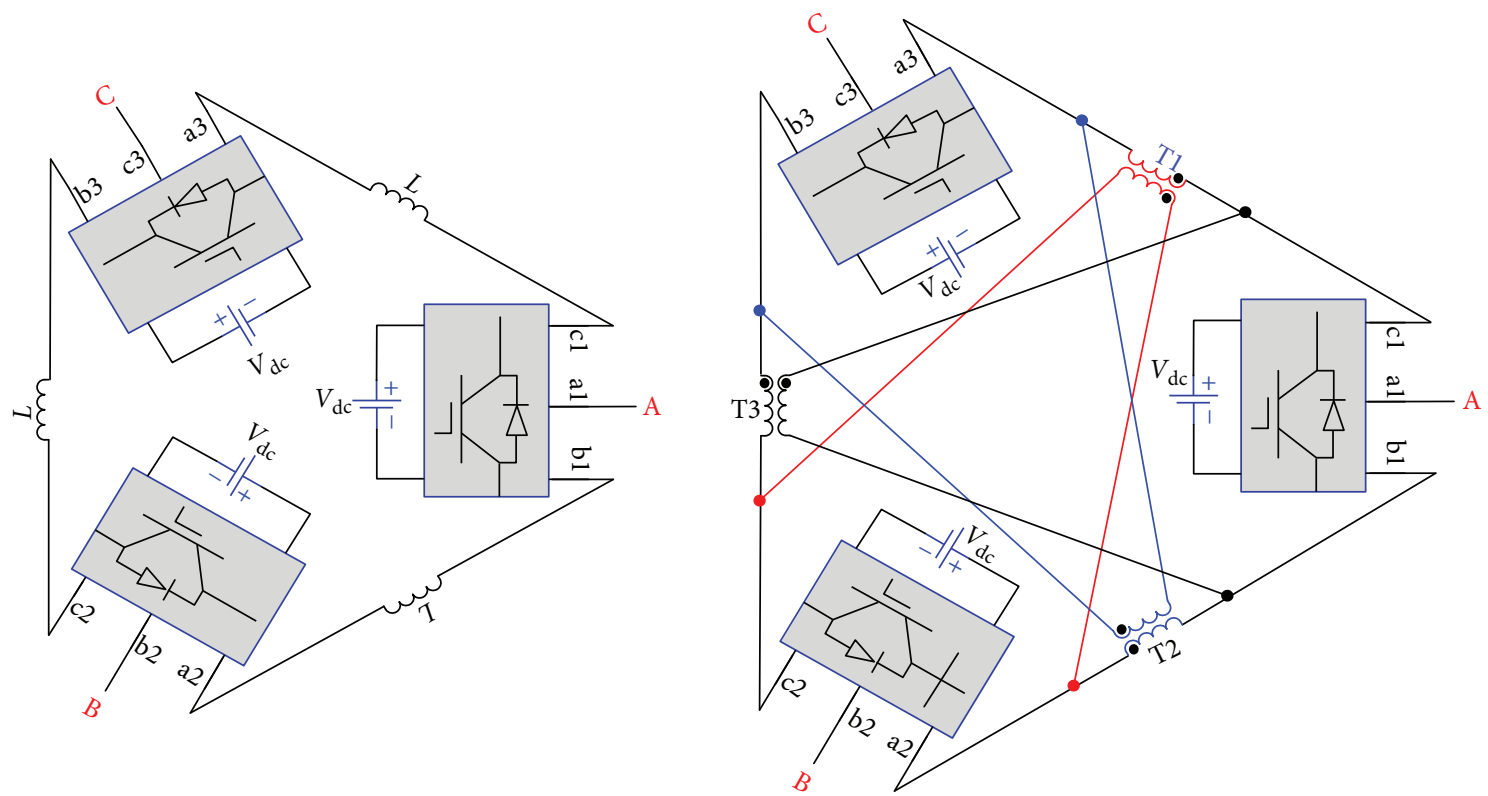

Figure 1: Topologies of cascade two-level converters.

VSCs have been widely used in chemical, oil, and different kinds of plants, as well as in power plants, transmission systems, and PQ compensators [11].

Current research is mainly focused on three specific multilevel VSC topologies, namely, the neutral-point clamped (NPC) [12], flying capacitor (FC) [13] and the Cascaded $\mathrm{H}$-bridge (CHB) [14] topologies. The NPC VSC requires a high number of clamping diodes to increase the number of voltage levels, which can cause problems related to switches with different ratings, high-voltage rating in blocking diodes, and capacitor voltage imbalance. However, the FC VSC consists of a large number of capacitors, which leads to complications in regulating capacitor voltages. Finally, the $\mathrm{CHB}$ VSC provides isolated DC sources, hence being appropriate for use in PV systems [15]. In addition, other advantages of this topology include its modular structure and the reduced number of components compared to the other multilevel converters (i.e., NPC and FC). Therefore, the CHB VSC can reach the same number of voltage levels with a simpler assembly and maintenance. However, this topology presents three main drawbacks: (i) high overall component count; (ii) high energy storage requirement because the instantaneous power related to each $\mathrm{H}$-bridge varies at twice the fundamental frequency, given its single-phase modular structure; and (iii) difficulty to control the voltage across DC-link capacitors.

The concept of interconnecting three traditional threephase VSCs to produce a multilevel converter was first proposed in [16] and applied to medium-voltage variablespeed drives. In [17], three three-phase two-level VSCs are interconnected using three single-phase transformers with a $1: 1$ turn ratio. These interconnected transformers increase the output voltage and suppress the circulating current inside the converter. The power capacity of the overall converter is three times the capacity of each interconnected converter, whereas the volt-ampere rating of each intermediate transformer is equal to that of each interconnected converter. In [18], another topology known as the hexagram multilevel converter (HMC) is proposed, which combines six two-level converters by using six inductors. This topology shares many advantages of the $\mathrm{CHB}$ but uses fewer switches and reduces the size of the DC-link capacitor [19]. The advantages of the proposed topology can be summarized as follows: (1) only six standard three-phase VSCs are necessary to generate multilevel output voltage; (2) each VSC module is balanced in operation, equally loaded, and supplies $1 / 6$ output power; (3) modular construction which facilitates system maintenance and spare management; (4) only six isolated DC links with no voltage unbalance problem; (5) low number of power electronics switches and low DC energy storage requirement; and (6) the output transformer contributes to higher output voltage. Figures 1 and 2 are schematic diagrams illustrating multilevel topologies based on cascaded two-level VSCs according to previous research.

However, selecting an inductor with suitable inductance is no simple process, where the inductance value should be adequate to minimize the circulating current as well as to reduce an extra voltage drop on the inductors that affects the terminal voltage. This difficulty can be circumvented by using a multiwinding coupled inductor. Therefore, this paper analyzes the utilization of a multiwinding (e.g., two, three, and six windings) coupled inductor to interconnect the six VSCs instead of six single inductors. Consequently, both goals minimize the circulating current and the minimal effects to the output voltage can be accomplished instantaneously. Then, an analytical model to calculate the total inductance imposed to the circulating current path is derived. The equivalent circuit model of the HMC is detailed in the abc reference frame and then transformed into the orthogonal dq0 reference frame. Moreover, to extract the maximum power from the PV arrays, a control algorithm for maximum power point tracking is also presented. 


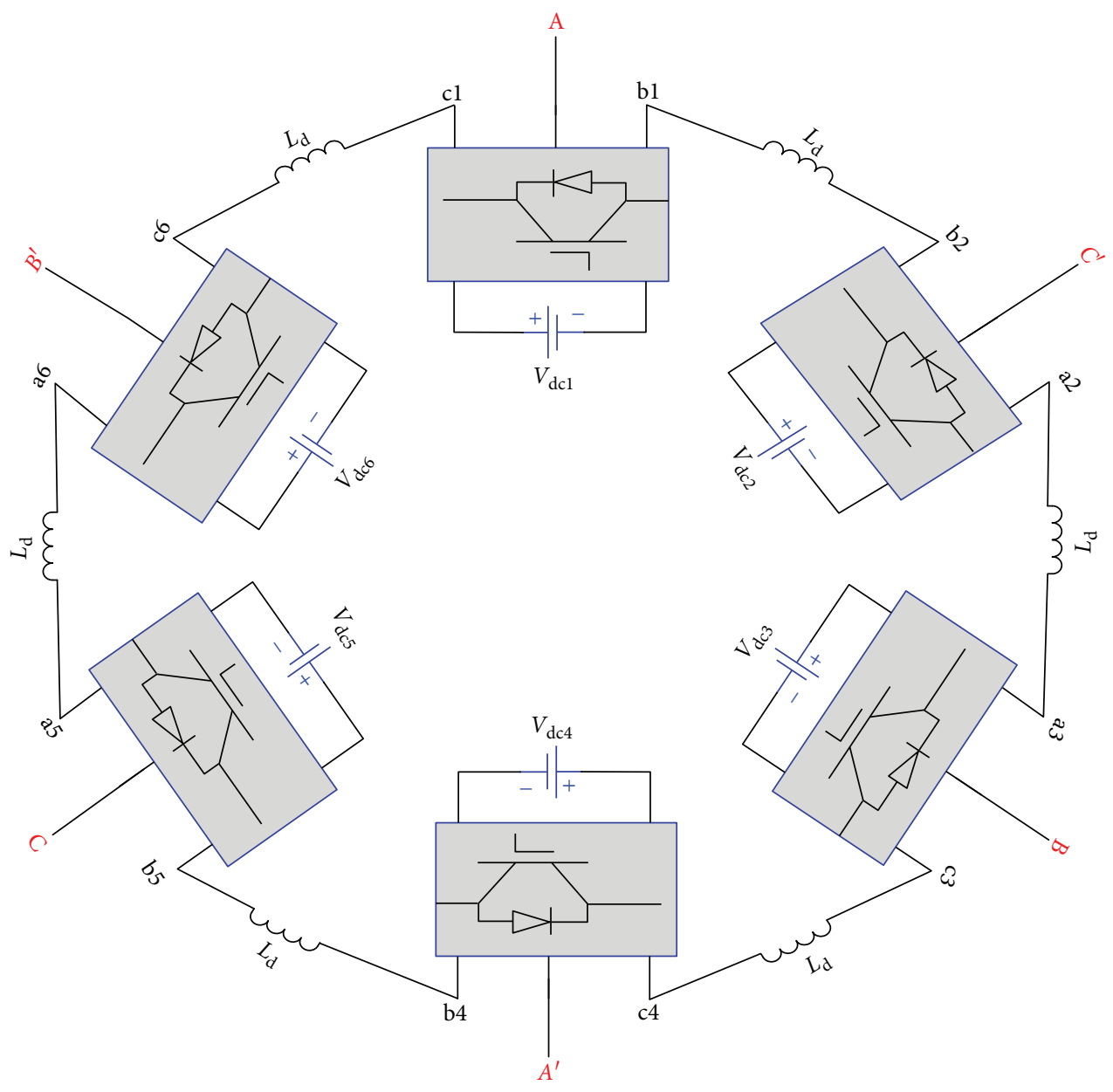

FIgURE 2: HMC electrical diagram.

The paper is organized as follows: Section 2 describes the HMC. Section 3 presents the mathematical model for a grid-connected PV system. Section 4 demonstrates the benefits of the multiwinding coupled inductor inside the HMC. Section 5 describes the control system and modulation strategy. Section 6 shows the simulation results followed by the corresponding discussion. Finally, the conclusions achieved from the present work are summarized in Section 7.

\section{System Description}

The proposed configuration of the three-phase gridconnected PV plants is shown in Figure 3. This configuration is composed of six traditional three-phase two-level VSC modules, which have a hexagonal interconnection to produce higher voltage levels as shown in Figure 2. The circulating current in the obtained loop can be suppressed using six inductors, which present a small impedance at the switching frequency. Each VSC module supplies 1/6 of the converter output power. In addition, each module has one of its AC terminals (i.e., a, b, or c) designated as converter output. The three-phase AC output terminals of the HMC are labeled as follows: A (AC terminal a1 of module 1), B (AC terminal b3 of module 3 ), and $\mathrm{C}$ (AC terminal c5 of module 5 ). The remaining three-phase $\mathrm{AC}$ output terminals are labeled as follows: $\mathrm{A}^{\prime}$ (AC terminal a4 of module 4), B' (AC terminal b6 of module 6 ), and $C^{\prime}$ (AC terminal $c 2$ of module 2 ). The other two AC terminals of each module are, respectively, connected to an adjacent module through an inductor. For instance, AC terminal b1 of module 1 is coupled to AC terminal b2 of module 2 through an inductor $L_{\mathrm{d}}$; AC terminal $\mathrm{cl}$ of module 1 is coupled to AC terminal c6 of module 6 through another inductor. The remaining modules consist of similar connections, as shown in Figure 2.

As shown in Figure 3, the PV system based on the HMC has six output terminals. Therefore, when linked to the three-phase electrical grid, an open-end winding (OEW) transformer is necessary to provide these six terminals. The secondary windings of the OEW transformer are connected differentially. In the proposed converter, AC terminals $A-A^{\prime}, B-B^{\prime}$, and $C-C^{\prime}$ are used to provide phases $\mathrm{A}, \mathrm{B}$, and $\mathrm{C}$, respectively. High-voltage windings are arranged in a star configuration and coupled directly to the three-phase grid. Each VSC module is supplied with a separate PV string to produce two-level individual 


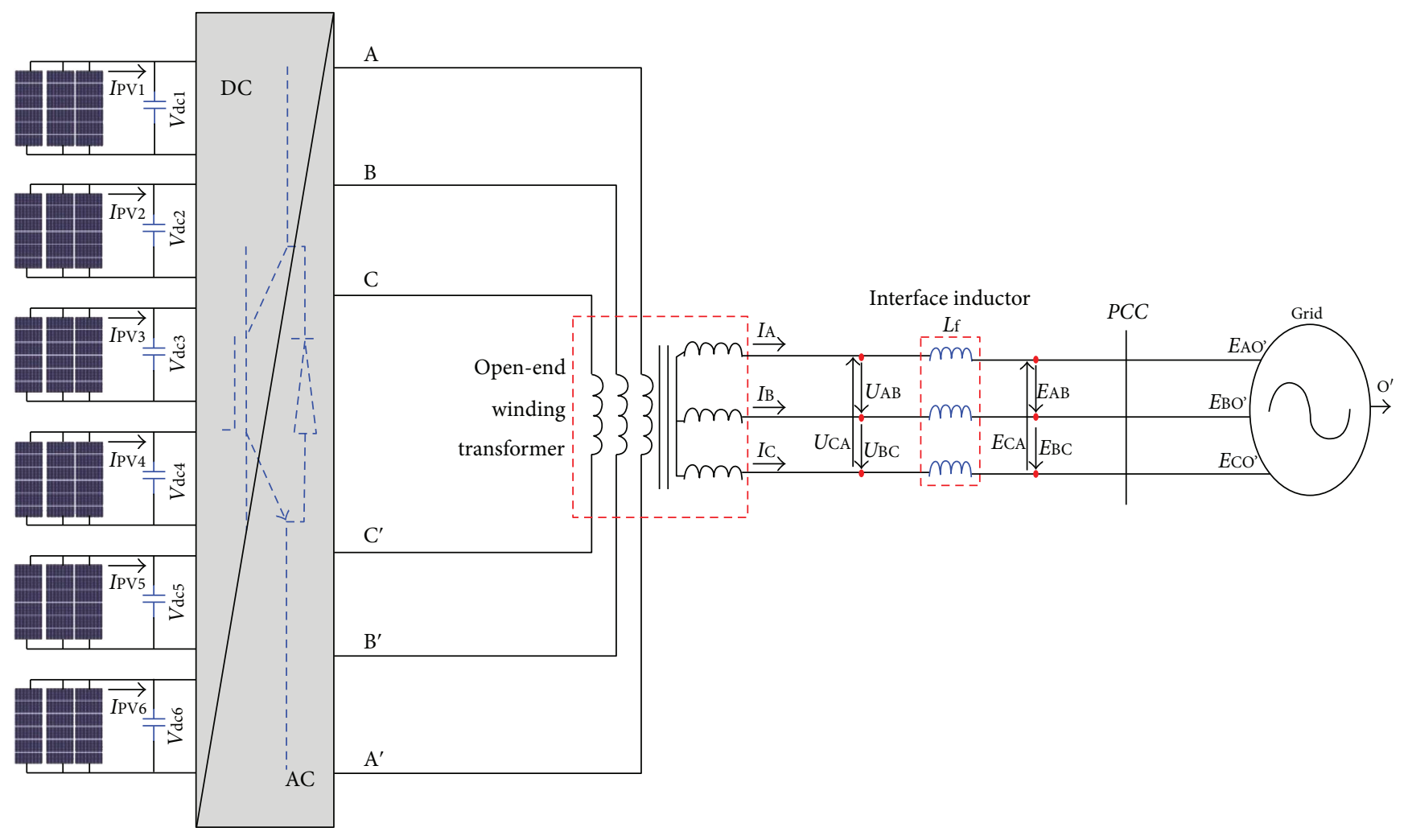

FIgURE 3: Complete HMC for a grid-connected PV system.

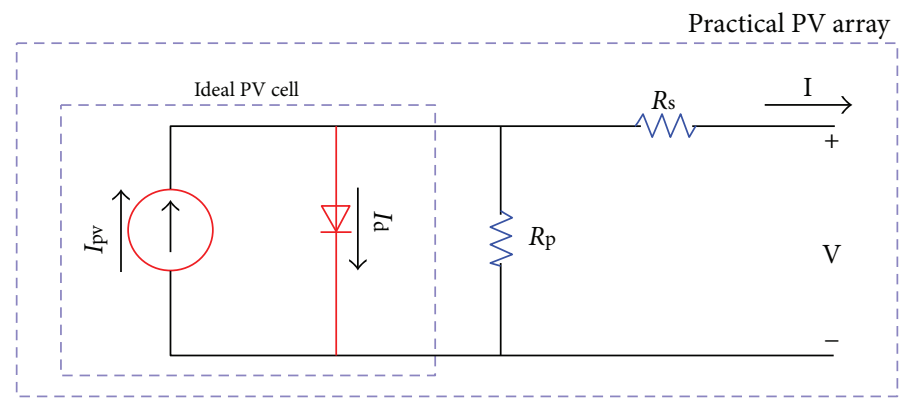

FIgURE 4: Equivalent model of a PV array.

outputs. The proposed converter topology presents several advantages, such as the use of fewer power electronic switches, diodes, and storage capacitors when compared with other topologies, making it suitable for renewable energy and other applications.

\section{System Modeling}

3.1. PV System Modeling and MPPT Control. Figure 4 shows the equivalent model of a PV array. The PV array is composed of several series-parallel connected solar cells. The basic equation of the PV array is given by [20].

$$
I=I_{\mathrm{pv}}-I_{0}\left[\exp \left(\frac{V+R_{\mathrm{s}} I}{a V_{\mathrm{t}}}\right)-1\right]-\frac{V+R_{\mathrm{s}} I}{R_{\mathrm{p}}}
$$

where $I_{\mathrm{pv}}=N_{\mathrm{p}} I_{\mathrm{pv}, \text { cell }}$ is the PV current of the array, $I_{\mathrm{pv}, \text { cell }}$ is the current generated by incident light (directly proportional to Sun irradiation), $N_{\mathrm{p}}$ is the number of cells connected in parallel, $I_{0}=N_{\mathrm{p}} I_{0, \text { cell }}$ is the saturation current of the array, $I_{0, \text { cell }}$ is the reverse saturation or leakage current of the diode, $V_{\mathrm{t}}=N_{\mathrm{s}} k T / q$ is the thermal voltage of the array, $N_{\mathrm{s}}$ is the number of cells connected in series, $q$ is the electron charge, $k$ is the Boltzmann constant, $T$ is the temperature of the p-n junction, $a$ is the diode ideality constant, $R_{\mathrm{s}}$ is the equivalent series resistance of the array, and $R_{\mathrm{p}}$ is the equivalent parallel resistance. Table 1 shows the nominal parameters of the KC200GT PV array. Figure 5 shows the I-V and P-V curves obtained using (1) of the PV array under variable solar radiation. 
TABle 1: Parameters of the KC200GT PV array at $25^{\circ} \mathrm{C}, \mathrm{AM} 1.5$, and $1000 \mathrm{~W} / \mathrm{m}^{2}$.

\begin{tabular}{|c|c|c|c|c|c|c|c|c|c|c|c|}
\hline $\begin{array}{l}I_{\mathrm{mp}} \\
(\mathrm{A})\end{array}$ & $\begin{array}{l}V_{\mathrm{mp}} \\
(\mathrm{V})\end{array}$ & $\begin{array}{l}P_{\max } \\
(\mathrm{W})\end{array}$ & $\begin{array}{l}I_{\mathrm{sc}} \\
(\mathrm{A})\end{array}$ & $\begin{array}{l}V_{\mathrm{oc}} \\
(\mathrm{V})\end{array}$ & $\begin{array}{c}K_{\mathrm{v}} \\
(\mathrm{V} / \mathrm{K})\end{array}$ & $\begin{array}{c}K_{\mathrm{I}} \\
(\mathrm{A} / \mathrm{K})\end{array}$ & $\begin{array}{c}N_{\text {ss }} \\
\text { (No.) }\end{array}$ & $\begin{array}{l}R_{\mathrm{p}} \\
(\Omega)\end{array}$ & $\begin{array}{l}R_{\mathrm{s}} \\
(\Omega)\end{array}$ & $\begin{array}{l}I_{\mathrm{o}, \mathrm{n}} \\
(\mathrm{A})\end{array}$ & $a$ \\
\hline 7.61 & 26.3 & 200.143 & 8.21 & 32.9 & -0.123 & 0.0032 & 54 & 415.405 & 0.221 & $9.825 \times 10^{-8}$ & 1.3 \\
\hline
\end{tabular}

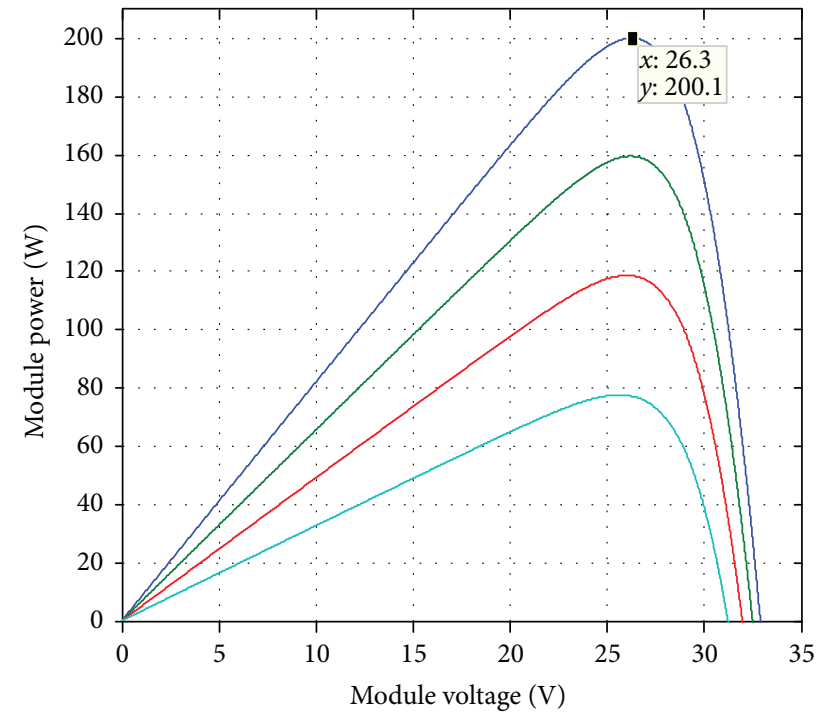

$\begin{array}{lll}\text { P-V curve @ } 1000 \mathrm{~W} / \mathrm{m}^{2} & \text { P-V curve } @ 600 \mathrm{~W} / \mathrm{m}^{2} \\ & \text { P-V curve } @ 800 \mathrm{~W} / \mathrm{m}^{2} & \text { P-V curve } @ 400 \mathrm{~W} / \mathrm{m}^{2}\end{array}$

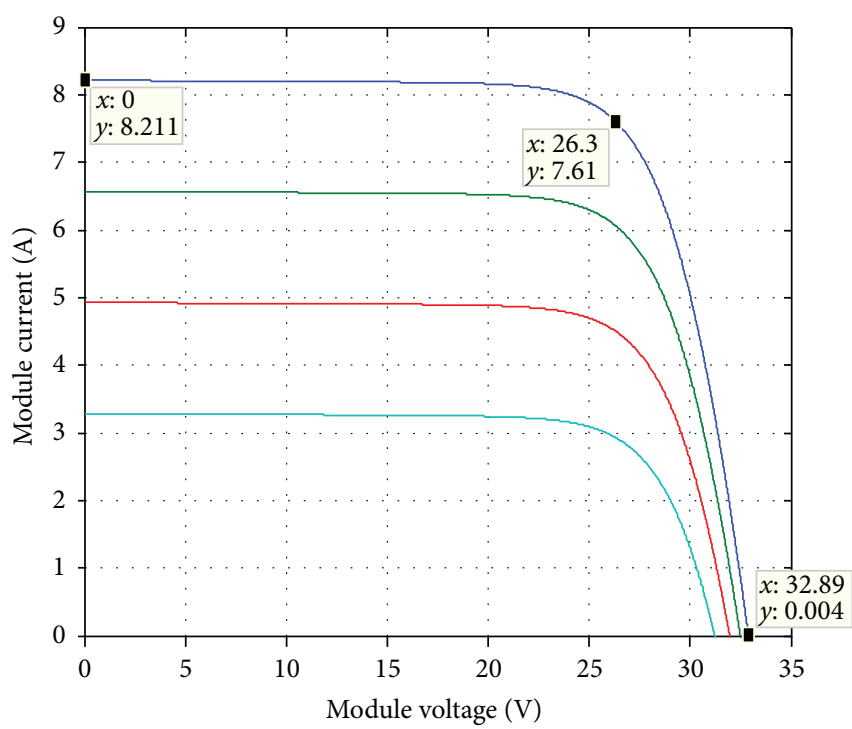

$\begin{array}{ll}\text { I-V curve } @ 1000 \mathrm{~W} / \mathrm{m}^{2} & -\mathrm{I}-\mathrm{V} \text { curve } @ 600 \mathrm{~W} / \mathrm{m}^{2} \\ -\mathrm{I}-\mathrm{V} \text { curve } @ 800 \mathrm{~W} / \mathrm{m}^{2} & \mathrm{I}-\mathrm{V} \text { curve } @ 400 \mathrm{~W} / \mathrm{m}^{2}\end{array}$

Figure 5: I-V and P-V curves of the KC200GT PV array.

3.2. Maximum Power Point Tracking. The proposed system consists of 12 PV modules distributed as six pairs of seriesconnected modules and coupled directly to a single DC link (see Figure 3). Therefore, the power rating of the proposed converter is $2.4 \mathrm{~kW}$. The controller is aimed to regulate the voltage of the PV-module pair at $52.6 \mathrm{~V}$, to guarantee maximum power transfer to the grid.

Next, the aim of the MPPT control algorithm used in this paper is to ensure that under any solar radiation and temperature conditions, the maximum power is extracted from the $\mathrm{PV}$ modules. This is achieved by matching the PV-array maximum power point to the corresponding operating voltage and current of the converters. The perturb and observe (P\&O) algorithm is a commonly used MPPT technique because it is easy to implement [21]. The operating principle of the $\mathrm{P} \& \mathrm{O}$ algorithm is shown in Figure 6. This algorithm measures the PV plant voltage and current, then it varies the operating voltage and compares the power received between the two voltage values. After each perturbation, the algorithm compares the output power from the PV before and after the perturbation. The direction of a new perturbation depends upon the output power: the perturbation will follow the same direction if higher power is measured when the output voltage varies and the opposite direction otherwise. These procedures are repeated continuously, and the reference voltage is generated and fed to the converter controller.
The numerical illustration of the $\mathrm{P} \& \mathrm{O}$ algorithm [2] is given as follows:

$$
\frac{d P_{\mathrm{pv}}(k)}{d V_{\mathrm{pv}}(k)}=\frac{P_{\mathrm{pv}}(k)-P_{\mathrm{pv}}(k-1)}{V_{\mathrm{pv}}(k)-V_{\mathrm{pv}}(k-1)} .
$$

Here, $P_{\mathrm{pv}}(k)$ and $P_{\mathrm{pv}}(k-1)$ stand for current power and previous measured power, while $V_{\mathrm{pv}}(k)$ and $V_{\mathrm{pv}}(k-1)$ stand for current PV voltage and previous one.

3.3. Voltage and Current Analysis. Under the symmetrical operation condition, the fundamental components of the six VSC modules are the same. The corresponding opencircuit voltage of the HMC is presented in Figure 7.

3.3.1. Current Relations. The phase currents of each VSC modules fulfill the following expressions:

$$
\left[\begin{array}{c}
i_{\mathrm{a} 1}+i_{\mathrm{b} 1}+i_{\mathrm{c} 1} \\
i_{\mathrm{a} 2}+i_{\mathrm{b} 2}+i_{\mathrm{c} 2} \\
i_{\mathrm{a} 3}+i_{\mathrm{b} 3}+i_{\mathrm{c} 3} \\
i_{\mathrm{a} 4}+i_{\mathrm{b} 4}+i_{\mathrm{c} 4} \\
i_{\mathrm{a} 5}+i_{\mathrm{b} 5}+i_{\mathrm{c} 5} \\
i_{\mathrm{a} 6}+i_{\mathrm{b} 6}+i_{\mathrm{c} 6}
\end{array}\right]=0 .
$$




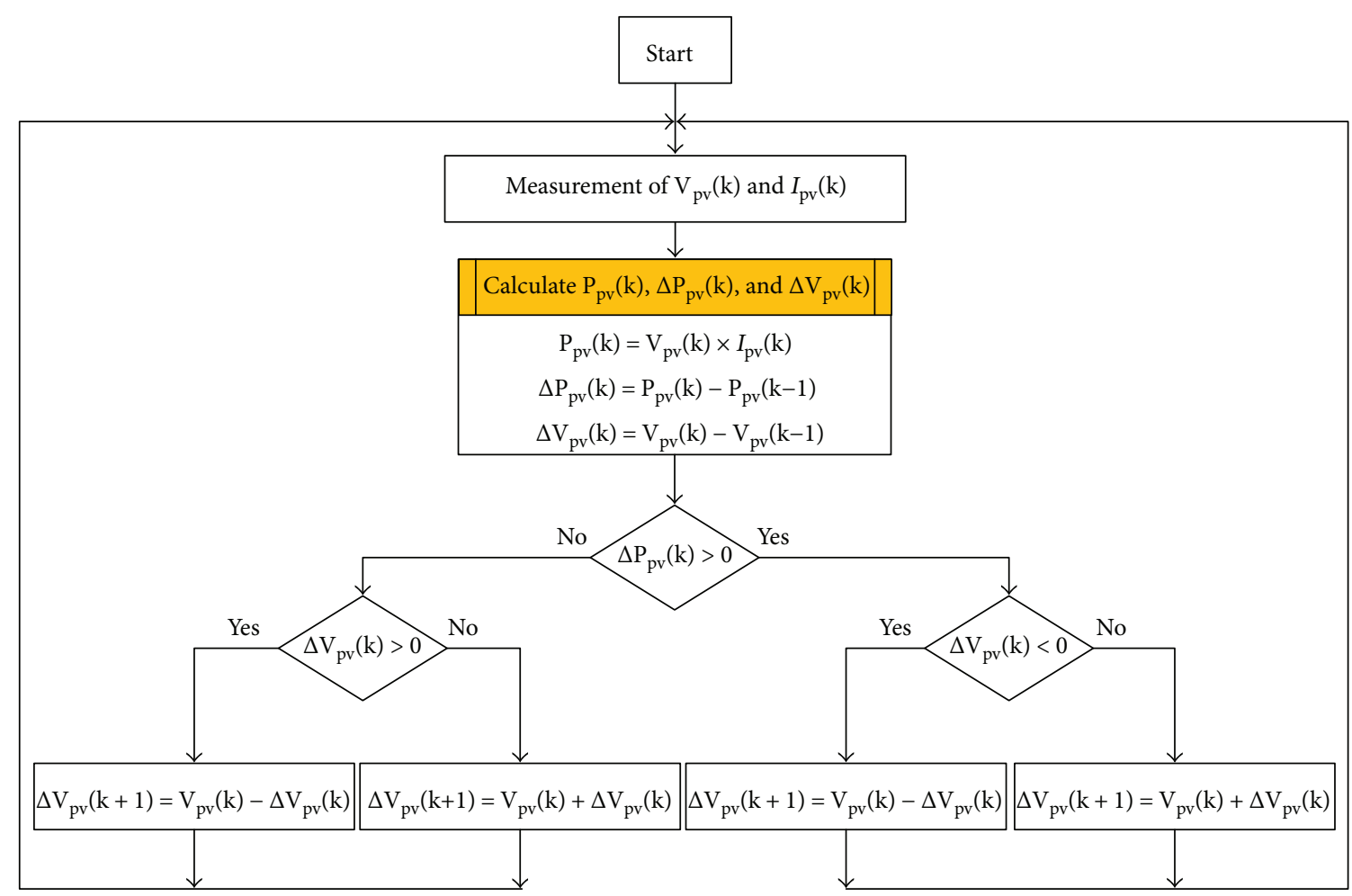

Figure 6: Flowchart for P\&O MPPT method.

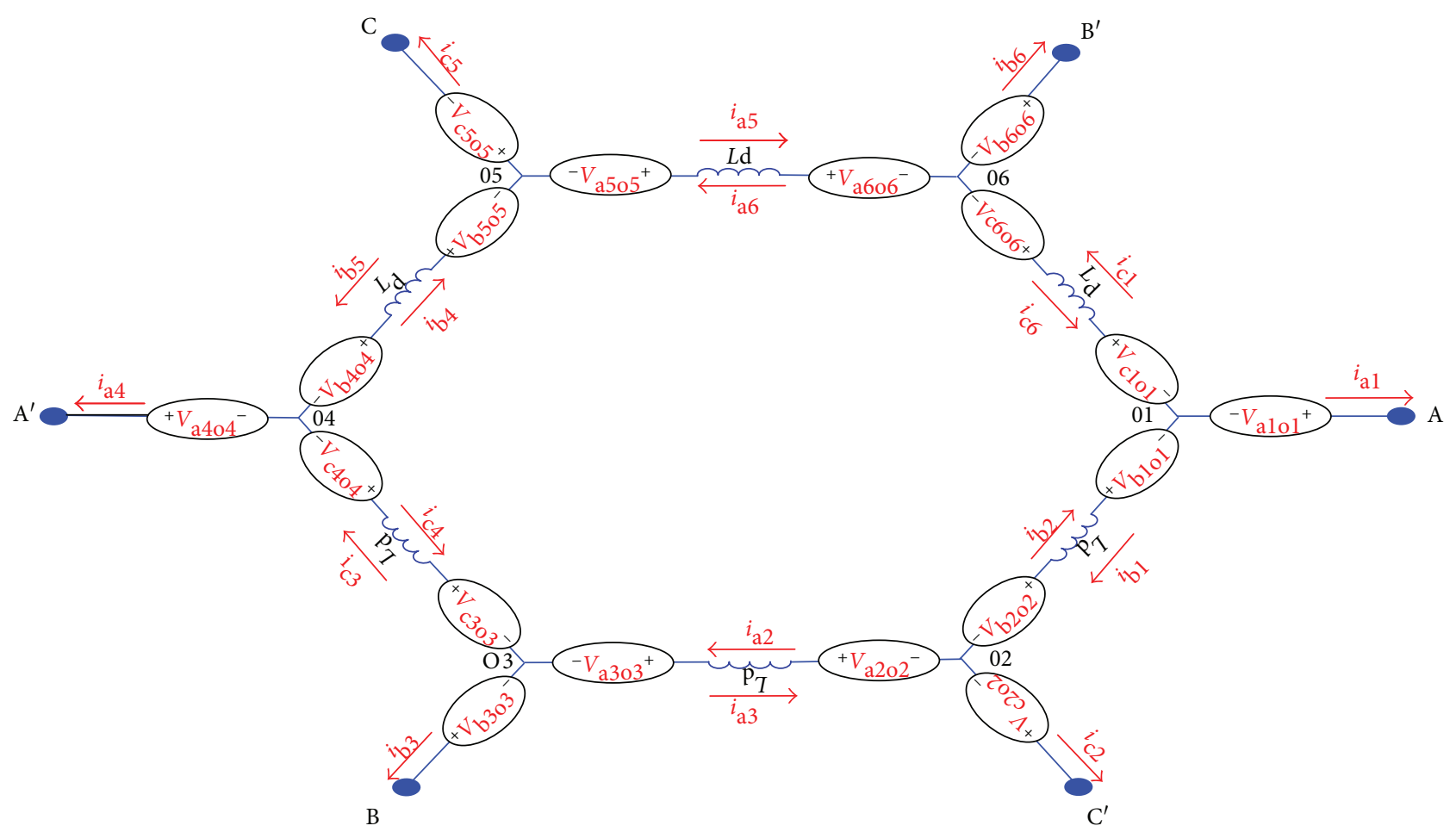

Figure 7: Phasor voltage of the HMC. 
Assuming that the intermediate coupled inductors have large magnetizing inductance, the circulating currents are suppressed to a low value and can be ignored, hence

$$
i_{\mathrm{b} 1}+i_{\mathrm{a} 2}+i_{\mathrm{c} 3}+i_{\mathrm{b} 4}+i_{\mathrm{a} 5}+i_{\mathrm{c} 6}=0 .
$$

Because every pair of the six VSC modules is coupled, the current within the proposed converter has the following expressions:

$$
\left[\begin{array}{c}
i_{\mathrm{b} 1} \\
i_{\mathrm{a} 2} \\
i_{\mathrm{c} 3} \\
i_{\mathrm{b} 4} \\
i_{\mathrm{a} 5} \\
i_{\mathrm{c} 6}
\end{array}\right]=-\left[\begin{array}{c}
i_{\mathrm{b} 2} \\
i_{\mathrm{a} 3} \\
i_{\mathrm{c} 4} \\
i_{\mathrm{b} 5} \\
i_{\mathrm{a} 6} \\
i_{\mathrm{c} 1}
\end{array}\right] .
$$

Next, suppose that the HMC is linked to a threephase grid. Then, the output currents will satisfy the following equation:

$$
\left[\begin{array}{c}
I_{\mathrm{A}} \\
I_{\mathrm{B}} \\
I_{\mathrm{C}}
\end{array}\right]=\left[\begin{array}{c}
i_{\mathrm{a} 1} \\
i_{\mathrm{b} 3} \\
i_{\mathrm{c} 5}
\end{array}\right]=-\left[\begin{array}{c}
i_{\mathrm{a} 4} \\
i_{\mathrm{b} 6} \\
i_{\mathrm{c} 2}
\end{array}\right]=\left[\begin{array}{c}
I\lfloor 0 \\
I\lfloor-120 \\
I\lfloor+120
\end{array}\right] .
$$

Using (2), (3), and (4), the output current of each VSC module can be shown to be

$$
\begin{aligned}
{\left[\begin{array}{l}
i_{\mathrm{a} 1} \\
i_{\mathrm{b} 1} \\
i_{\mathrm{c} 1}
\end{array}\right] } & =\left[\begin{array}{l}
i_{\mathrm{a} 3} \\
i_{\mathrm{b} 3} \\
i_{\mathrm{c} 3}
\end{array}\right]=\left[\begin{array}{l}
i_{\mathrm{a} 5} \\
i_{\mathrm{b} 5} \\
i_{\mathrm{c} 5}
\end{array}\right]=-\left[\begin{array}{l}
i_{\mathrm{a} 2} \\
i_{\mathrm{b} 2} \\
i_{\mathrm{c} 2}
\end{array}\right]=-\left[\begin{array}{c}
i_{\mathrm{a} 4} \\
i_{\mathrm{b} 4} \\
i_{\mathrm{c} 4}
\end{array}\right]=-\left[\begin{array}{c}
i_{\mathrm{a} 6} \\
i_{\mathrm{b} 6} \\
i_{\mathrm{c} 6}
\end{array}\right] \\
& =\left[\begin{array}{c}
I_{\mathrm{A}} \\
I_{\mathrm{B}} \\
I_{\mathrm{C}}
\end{array}\right]=\left[\begin{array}{c}
I\lfloor 0 \\
I\lfloor-120 \\
I L+120
\end{array}\right],
\end{aligned}
$$

where $\left[I_{\mathrm{A}}, I_{\mathrm{B}}, I_{\mathrm{C}}\right]^{T}$ and $I$ are the converter output phase currents and their RMS values, respectively. It can be concluded from (5) that each VSC module within the HMC will have an identical current under the symmetrical operation condition.

3.3.2. Voltage Relations. Under the symmetrical operation condition, the fundamental component (RMS) of the phase voltages at the VSC modules can be described as

$$
\begin{aligned}
{\left[\begin{array}{c}
V_{\mathrm{a} 101} \\
V_{\mathrm{b} 101} \\
V_{\mathrm{c} 101}
\end{array}\right] } & =\left[\begin{array}{c}
V_{\mathrm{a} 303} \\
V_{\mathrm{b} 303} \\
V_{\mathrm{c} 303}
\end{array}\right]=\left[\begin{array}{c}
V_{\mathrm{a} 505} \\
V_{\mathrm{b} 505} \\
V_{\mathrm{c} 505}
\end{array}\right]=-\left[\begin{array}{c}
V_{\mathrm{a} 202} \\
V_{\mathrm{b} 202} \\
V_{\mathrm{c} 202}
\end{array}\right] \\
& =-\left[\begin{array}{c}
V_{\mathrm{a} 404} \\
V_{\mathrm{b} 404} \\
V_{\mathrm{c} 404}
\end{array}\right]=-\left[\begin{array}{c}
\mathrm{V}_{\mathrm{a} 606} \\
V_{\mathrm{b} 606} \\
V_{\mathrm{c} 606}
\end{array}\right]=\left[\begin{array}{c}
V\lfloor 0 \\
V\lfloor-120 \\
V\lfloor+120
\end{array}\right], \\
V & =\frac{1}{2 \sqrt{2}} V_{\mathrm{dc}} m_{\mathrm{a}},
\end{aligned}
$$

where $V, V_{\mathrm{dc}}$, and $m_{\mathrm{a}}$ are the RMS values of each VSCmodule phase voltage, the DC-link voltage of each VSC module, and the amplitude modulation index, respectively; subscripts o1, o2, o3, o4, o5, and o6 represent the virtual neutral points of each VSC.

The output voltages of the proposed converter are written as

$$
\begin{aligned}
{\left[\begin{array}{c}
V_{\mathrm{AA}^{\prime}} \\
V_{\mathrm{BB}^{\prime}} \\
V_{\mathrm{CC}^{\prime}}
\end{array}\right]=} & {\left[\begin{array}{l}
V_{\mathrm{a} 1 \mathrm{a} 4} \\
V_{\mathrm{b} 3 \mathrm{~b} 6} \\
V_{\mathrm{c} 2 \mathrm{c5}}
\end{array}\right] } \\
= & {\left[\begin{array}{l}
V_{\mathrm{a} 101}-V_{\mathrm{a} 404}+V_{\mathrm{c} 404}-V_{\mathrm{c} 303}+V_{\mathrm{a} 303}-V_{\mathrm{a} 202}+V_{\mathrm{b} 202}-V_{\mathrm{b} 101} \\
V_{\mathrm{b} 303}-V_{\mathrm{b} 606}+V_{\mathrm{a} 606}-V_{\mathrm{a} 505}+V_{\mathrm{b} 505}-V_{\mathrm{b} 404}+V_{\mathrm{c} 404}-V_{\mathrm{c} 303} \\
V_{\mathrm{c} 505}-V_{\mathrm{c} 202}+V_{\mathrm{b} 202}-V_{\mathrm{b} 101}+V_{\mathrm{c} 101}-V_{\mathrm{c} 606}+V_{\mathrm{a} 606}-V_{\mathrm{a} 505}
\end{array}\right] } \\
& -2 Z_{\mathrm{d}}\left[\begin{array}{c}
i_{\mathrm{a} 1} \\
i_{\mathrm{b} 3} \\
i_{\mathrm{c} 5}
\end{array}\right],
\end{aligned}
$$

where impedance $Z_{\mathrm{d}}=j \omega L_{\mathrm{d}}$.

Thus, using (5), (6), (7), and (8), the net output voltages of the HMC under the symmetrical operation condition are given by

$$
\left[\begin{array}{c}
V_{\mathrm{AA}^{\prime}} \\
V_{\mathrm{BB}^{\prime}} \\
V_{\mathrm{CC}^{\prime}}
\end{array}\right]=\left[\begin{array}{c}
V_{\mathrm{a} 1 a 4} \\
V_{\mathrm{b} 3 \mathrm{~b} 6} \\
V_{\mathrm{c} 2 \mathrm{c} 5}
\end{array}\right]=\left[\begin{array}{c}
6 V\lfloor 0 \\
6 V\lfloor-120 \\
6 V\lfloor+120
\end{array}\right]-2 Z_{\mathrm{d}}\left[\begin{array}{c}
I_{\mathrm{A}} \\
I_{\mathrm{B}} \\
I_{\mathrm{C}}
\end{array}\right] .
$$

Consequently, (9) demonstrates that the three-phase voltage of the HMC is approximately six times the phase voltage of each VSC module. In other words, the voltage stress is reduced by a factor of six.

3.4. Equivalent Circuit Model. Based on Figure 3, the line voltages of the HMC are expressed by 


$$
\begin{aligned}
{\left[\begin{array}{c}
U_{\mathrm{AB}} \\
U_{\mathrm{BC}} \\
U_{\mathrm{CA}}
\end{array}\right]=} & {\left[\begin{array}{c}
V_{\mathrm{AA}^{\prime}}-V_{\mathrm{BB}^{\prime}} \\
V_{\mathrm{BB}^{\prime}}-V_{\mathrm{CC}^{\prime}} \\
V_{\mathrm{CC}^{\prime}}-V_{\mathrm{AA}^{\prime}}
\end{array}\right]=\left[\begin{array}{c}
6 \sqrt{3} V\lfloor-30 \\
6 \sqrt{3} V\lfloor-150 \\
6 \sqrt{3} V\lfloor+90
\end{array}\right] } \\
& -2 j \omega L_{\mathrm{d}}\left[\begin{array}{c}
I_{\mathrm{A}}-I_{\mathrm{B}} \\
I_{\mathrm{B}}-I_{\mathrm{C}} \\
I_{\mathrm{C}}-I_{\mathrm{A}}
\end{array}\right]=\left[\begin{array}{c}
E_{\mathrm{AB}} \\
E_{\mathrm{BC}} \\
E_{\mathrm{CA}}
\end{array}\right] \\
& +j \omega L_{\mathrm{f}}\left[\begin{array}{c}
I_{\mathrm{A}} \\
I_{\mathrm{B}} \\
I_{\mathrm{C}}
\end{array}\right]-j \omega L_{\mathrm{f}}\left[\begin{array}{c}
I_{\mathrm{B}} \\
I_{\mathrm{C}} \\
I_{\mathrm{A}}
\end{array}\right],
\end{aligned}
$$

where $\left[E_{\mathrm{AB}}, E_{\mathrm{BC}}, E_{\mathrm{CA}}\right]^{T}$ are the RMS values of the line-to-line voltages in the grid, $\left[U_{\mathrm{AB}}, U_{\mathrm{BC}}, U_{\mathrm{CA}}\right]^{T}$ and $\left[I_{\mathrm{A}}, I_{\mathrm{B}}, I_{\mathrm{C}}\right]^{T}$ are the RMS values of line voltages and the RMS values of the output current, respectively, and $L_{\mathrm{f}}$ is the AC-side filtering inductance.

When the conversion powers between the VSC modules within the HMC are balanced, the six DC-link voltages are equal to $V_{\text {DCav }}$, hence

$$
\begin{aligned}
V_{\mathrm{DCav}} & =V_{\mathrm{dc} 1}=V_{\mathrm{dc2}}=V_{\mathrm{dc3}}=V_{\mathrm{dc} 4}=V_{\mathrm{dc5}} \\
& =V_{\mathrm{dc} 6}=\frac{V_{\mathrm{dc1}}+V_{\mathrm{dc2}}+V_{\mathrm{dc} 3}+V_{\mathrm{dc} 4}+V_{\mathrm{dc5}}+V_{\mathrm{dc} 6}}{6} .
\end{aligned}
$$

Moreover, the equivalent DC-link voltage can be expressed as

$$
U_{\text {DC_eq }}=6 V_{\text {DC_av }} \text {. }
$$

If each VSC is driven using the same PWM, the relationship between the DC-link voltages and the phase voltages can be expressed as

$$
V=\frac{1}{2 \sqrt{2}} U_{\text {DC_eq }} m_{\mathrm{a}} .
$$

From (12) and (14), the HMC can be modeled by

$$
\left[\begin{array}{c}
\overline{U_{\mathrm{AB}}} \\
\overline{U_{\mathrm{BC}}} \\
\overline{U_{\mathrm{CA}}}
\end{array}\right]=\left[\begin{array}{c}
E_{\mathrm{AB}} \\
E_{\mathrm{BC}} \\
E_{\mathrm{CA}}
\end{array}\right]+j \omega\left(L_{\mathrm{f}}+2 L_{\mathrm{d}}\right)\left[\begin{array}{c}
I_{\mathrm{A}} \\
I_{\mathrm{B}} \\
I_{\mathrm{C}}
\end{array}\right]-j \omega\left(L_{\mathrm{f}}+2 L_{\mathrm{d}}\right)\left[\begin{array}{c}
I_{\mathrm{B}} \\
I_{\mathrm{C}} \\
I_{\mathrm{A}}
\end{array}\right] \text {, }
$$

where

$$
\left[\begin{array}{c}
\overline{U_{\mathrm{AB}}} \\
\overline{U_{\mathrm{BC}}} \\
\overline{U_{\mathrm{CA}}}
\end{array}\right]=\left[\begin{array}{c}
6 \sqrt{3} V\lfloor-30 \\
6 \sqrt{3} V\lfloor-150 \\
6 \sqrt{3} V\lfloor+90
\end{array}\right] .
$$

Using (14) and (17), the HMC can be modeled as a conventional three-phase two-level VSC, as shown in Figure 8.
Figure 8 shows the equivalent circuit model of the HMC. The equivalent circuit is composed of an opencircuit voltage source linked in series to the HMC output impedance. The open-circuit voltage of the HMC is shown in Figure 7. As shown in Figure 8, the equivalent interface inductor of the HMC is $2 L_{\mathrm{d}}+L_{\mathrm{f}}$. This feature is advantageous, because the filtering inductor $L_{\mathrm{f}}$ could be minimalized or even removed. However, this can be inopportune when the line transformer has sufficient inductance for filtering the output current. In this case, essentially if the HMC supplies reactive power, the output impedance causes a voltage drop, decreasing the power capability. Thus, it might be better to minimize the interconnected total inductances. However, the inductances are essential to suppress the circulating current within the HMC. The aforementioned decision shows that the interconnected inductance value selection is not a simple process, where the inductance should be large enough to minimize the circulating current but small enough to avoid an extra voltage drop. In the following section, this feature is investigated using multiwinding coupled inductors.

\section{The Role of the Coupled Inductors}

The function of the multiwinding coupled inductors within the HMC is investigated in this section. The HMC performance analysis can be demonstrated based on the function of the coupled inductors. The six VSC modules are interconnected to each other, creating a hexagon as explained in Section 3.4. However, instead of using six inductors, multiwinding coupled inductors are used to interconnect the VSC modules.

4.1. HMC with Three Two-Winding Coupled Inductors. Two inductors with an equal number of turns are coupled together; that is, the input to one side will produce an output on both, as shown in Figure 9. Since the turn ratio of the coupled inductor is approximately $1: 1$, the self-inductances of the primary and secondary windings are the same (e.g., $\left.L_{\mathrm{p}}=L_{\mathrm{s}}=L_{\mathrm{B}}\right)$. Applying the voltage relationships of coupled inductors, the following equations are given:

$$
v_{\mathrm{b} 1 \mathrm{~b} 2}=L_{11} \frac{d i_{\mathrm{b} 1}}{d t}+L_{12} \frac{d i_{\mathrm{b} 5}}{d t},
$$

and

$$
v_{\mathrm{b} 5 \mathrm{~b} 4}=L_{22} \frac{d i_{\mathrm{b} 5}}{d t}+L_{21} \frac{d i_{\mathrm{b} 1}}{d t},
$$

where $L_{22}=L_{11}=L_{\mathrm{B}}+L_{\mathrm{m}}, L_{\mathrm{m}}=L_{21}=L_{12}, i_{\mathrm{b} 1}=i_{\mathrm{b} 1}+i_{\text {cir }}$, and $i_{\mathrm{b} 5}=-i_{\mathrm{b} 1}+i_{\mathrm{cir}}$, and where $i_{x}(x=a, b, c)$ is the line current, $L_{\mathrm{B}}$ is the leakage inductance of the inductor windings, which is expected to be identical for all windings, and $L_{\mathrm{m}}$ is the magnetizing inductance of the coupled inductor.

It is obvious in Figure 10 that the voltage drop on one of the coupled inductors is

$$
v=v_{\mathrm{b} 1 \mathrm{~b} 2}+v_{\mathrm{b} 5 \mathrm{~b} 4} .
$$




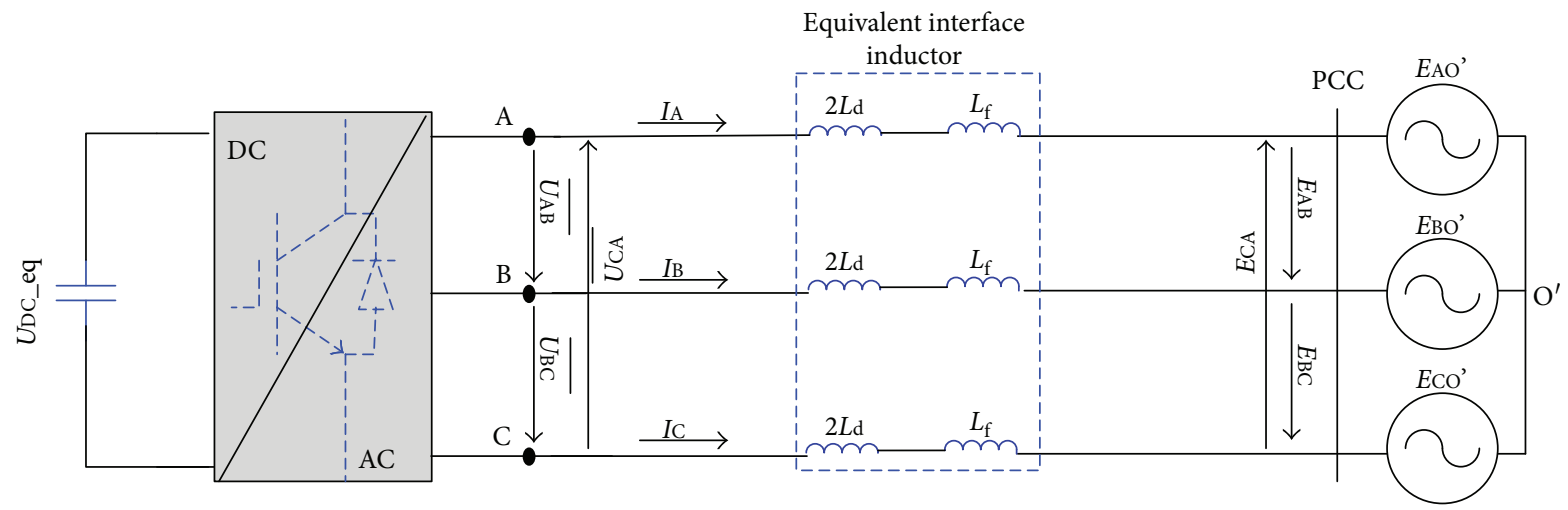

FIgURE 8: Equivalent circuit model of HMC.

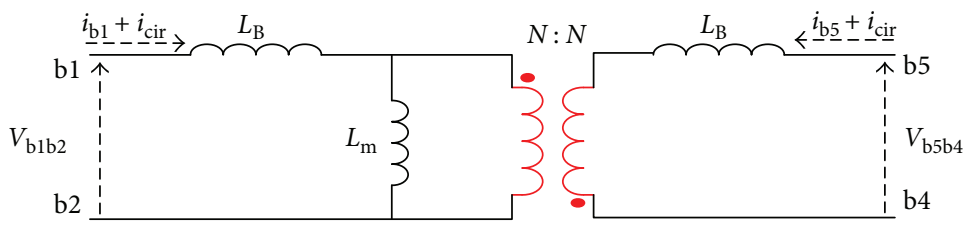

FIGURE 9: Equivalent circuit of the two-winding coupled inductor.

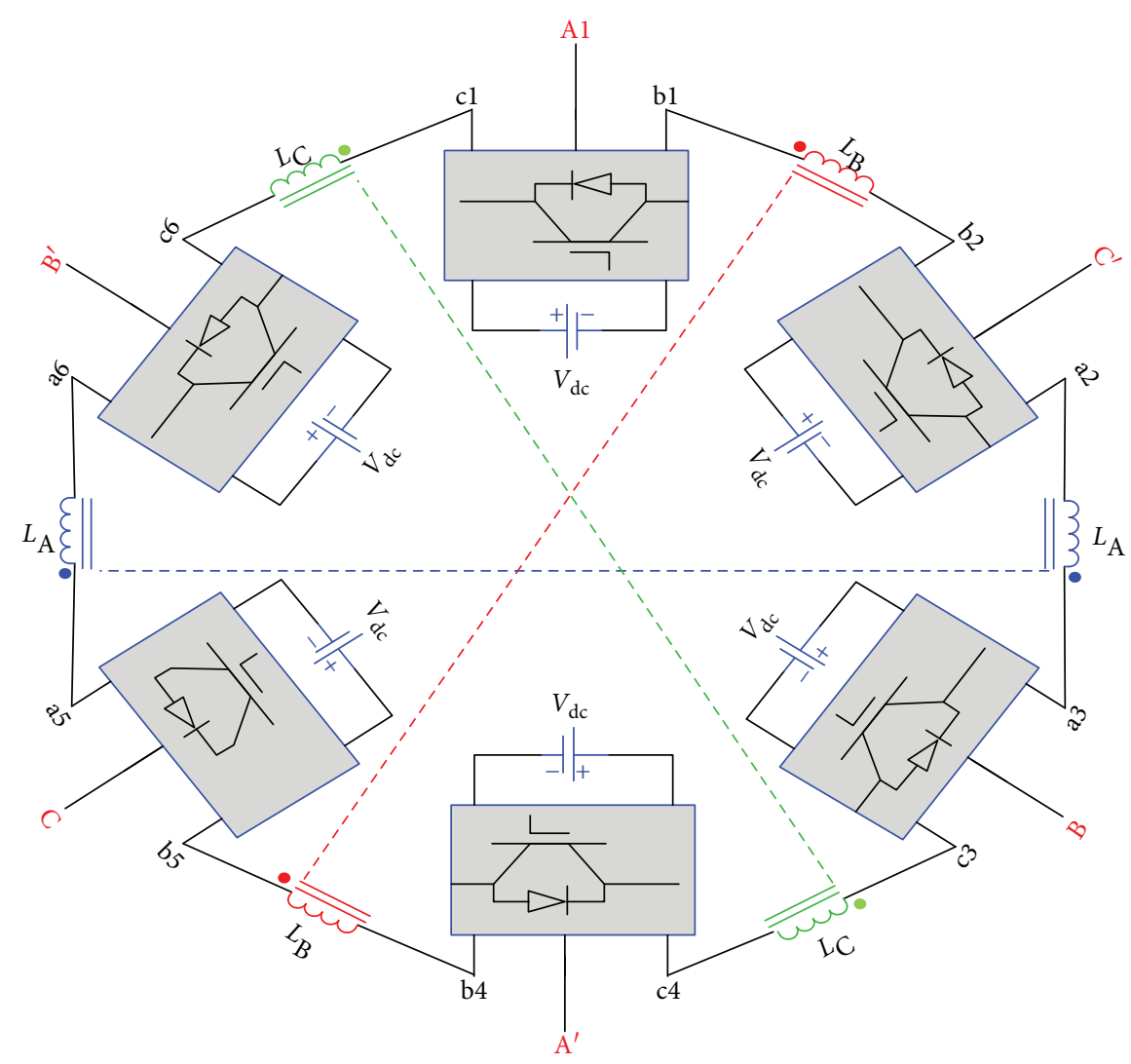

FIgURE 10: The HMC with three two-winding coupled inductors. 


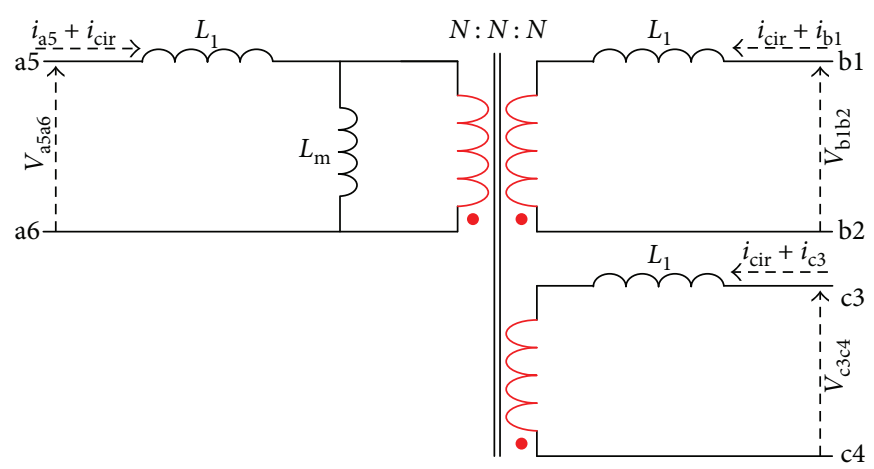

FIGURE 11: Equivalent circuit of the three-winding coupled inductor.

Using (18) and (19), the voltage across the coupled inductor can be expressed as

$$
\begin{aligned}
v= & \left(L_{\mathrm{B}}+L_{\mathrm{m}}\right) \frac{d\left(i_{\mathrm{b} 1}+i_{\mathrm{cir}}\right)}{d t}+L_{\mathrm{m}} \frac{d\left(-i_{\mathrm{b} 1}+i_{\mathrm{cir}}\right)}{d t} \\
& +\left(L_{\mathrm{B}}+L_{\mathrm{m}}\right) \frac{d\left(-i_{\mathrm{b} 1}+i_{\text {cir }}\right)}{d t}+L_{\mathrm{m}} \frac{d\left(i_{\mathrm{b} 1}+i_{\text {cir }}\right)}{d t}, \\
v= & \left(2 L_{\mathrm{B}}+4 L_{\mathrm{m}}\right) \frac{d\left(i_{\text {cir }}\right)}{d t} .
\end{aligned}
$$

Therefore, the total voltage drop across the three coupled inductors can be expressed as

$$
v_{\text {total }}=3\left(2 L_{\mathrm{B}}+4 L_{\mathrm{m}}\right) \frac{d\left(i_{\text {cir }}\right)}{d t}=\left(6 L_{\mathrm{B}}+12 L_{\mathrm{m}}\right) \frac{d\left(i_{\text {cir }}\right)}{d t} .
$$

4.2. HMC with Two Three-Winding Coupled Inductors. Three inductors with an equal number of turns are coupled together as shown in Figure 11. Writing the voltage equations of one coupled inductor with winding inductance Z1, the following equations are given:

$$
\begin{aligned}
& v_{\mathrm{a} 5 \mathrm{a} 6}=L_{\mathrm{a}} \frac{d i_{\mathrm{a}}}{d t}+L_{\mathrm{ab}} \frac{d i_{\mathrm{b}}}{d t}+L_{\mathrm{ac}} \frac{d i_{\mathrm{c}}}{d t}, \\
& v_{\mathrm{b} 1 \mathrm{~b} 2}=L_{\mathrm{b}} \frac{d i_{\mathrm{b}}}{d t}+L_{\mathrm{ba}} \frac{d i_{\mathrm{a}}}{d t}+L_{\mathrm{bc}} \frac{d i_{\mathrm{c}}}{d t}, \\
& v_{\mathrm{c} 3 \mathrm{c} 4}=L_{\mathrm{c}} \frac{d i_{\mathrm{c}}}{d t}+L_{\mathrm{ca}} \frac{d i_{\mathrm{a}}}{d t}+L_{\mathrm{cb}} \frac{d i_{\mathrm{b}}}{d t},
\end{aligned}
$$

where

$$
L_{\mathrm{a}}=L_{\mathrm{b}}=L_{\mathrm{c}}=L+L_{\mathrm{m}}, L_{\mathrm{m}}=L_{\mathrm{ab}}=L_{\mathrm{ba}}=L_{\mathrm{bc}}=L_{\mathrm{cb}}=L_{\mathrm{ca}}=L_{\mathrm{ac}},
$$

and

$$
\begin{aligned}
& i_{\mathrm{a}}=i_{\mathrm{a} 5}+i_{\mathrm{cir}}, \\
& i_{\mathrm{b}}=i_{\mathrm{b} 1}+i_{\mathrm{cir}}, \\
& i_{\mathrm{c}}=i_{\mathrm{c} 3}+i_{\mathrm{cir}},
\end{aligned}
$$

where $i_{\mathrm{x}}(x=a, b, c)$ is the line current, $L$ is the leakage inductance of the inductor windings, and $L_{\mathrm{m}}$ is the magnetizing inductance. It is obvious in Figure 12 that the voltage drop on the coupled inductor is

$$
v=v_{\mathrm{a} 5 \mathrm{a} 6}+v_{\mathrm{blb} 2}+v_{\mathrm{c} 3 \mathrm{c} 4} .
$$

Using (23), the voltage drop across one of the coupled inductor can be expressed as

$$
\begin{aligned}
v= & \left(L+L_{\mathrm{m}}\right) \frac{d\left(i_{\mathrm{a} 5}+i_{\mathrm{cir}}\right)}{d t}+L_{\mathrm{m}} \frac{d\left(i_{\mathrm{b} 1}+i_{\mathrm{cir}}\right)}{d t}+L_{\mathrm{m}} \frac{d\left(i_{\mathrm{c} 3}+i_{\mathrm{cir}}\right)}{d t} \\
& +\left(L+L_{\mathrm{m}}\right) \frac{d\left(i_{\mathrm{b} 1}+i_{\mathrm{cir}}\right)}{d t}+L_{\mathrm{m}} \frac{d\left(i_{\mathrm{a} 5}+i_{\mathrm{cir}}\right)}{d t}+L_{\mathrm{m}} \frac{d\left(i_{\mathrm{c} 3}+i_{\mathrm{cir}}\right)}{d t} \\
& +\left(L+L_{\mathrm{m}}\right) \frac{d\left(i_{\mathrm{c} 3}+i_{\mathrm{cir}}\right)}{d t}+L_{\mathrm{m}} \frac{d\left(i_{\mathrm{a} 5}+i_{\mathrm{cir}}\right)}{d t}+L_{\mathrm{m}} \frac{d\left(i_{\mathrm{b} 1}+i_{\mathrm{cir}}\right)}{d t}, \\
v= & \left(L+L_{\mathrm{m}}\right) \frac{d\left(i_{\mathrm{a} 5}+i_{\mathrm{b} 1}+i_{\mathrm{c} 3}\right)}{d t}+3\left(L+L_{\mathrm{m}}\right) \frac{d\left(i_{\mathrm{cir}}\right)}{d t} \\
& +2 L_{\mathrm{m}} \frac{d\left(i_{\mathrm{a} 5}+i_{\mathrm{b} 1}+i_{\mathrm{c} 3}\right)}{d t}+6 L_{\mathrm{m}} \frac{d\left(i_{\mathrm{cir}}\right)}{d t} .
\end{aligned}
$$

The voltage drop across the coupled inductor windings is

$$
v=\left(L+3 L_{\mathrm{m}}\right) \frac{d\left(i_{\mathrm{a} 5}+i_{\mathrm{b} 1}+i_{\mathrm{c} 3}\right)}{d t}+\left(3 L+9 L_{\mathrm{m}}\right) \frac{d\left(i_{\mathrm{cir}}\right)}{d t} .
$$

Under balanced conditions,

$$
i_{\mathrm{a} 5}+i_{\mathrm{b} 1}+i_{\mathrm{c} 3}=i_{\mathrm{a}}+i_{\mathrm{b}}+i_{\mathrm{c}}=0 .
$$

Accordingly, by applying (28) and (29), the voltage drop on the coupled inductor windings is

$$
v=\left(3 L+9 L_{\mathrm{m}}\right) \frac{d\left(i_{\text {cir }}\right)}{d t} .
$$

The total voltage drop across the two coupled inductors can be expressed as

$$
v_{\text {total }}=\left(6 L_{\mathrm{B}}+18 L_{\mathrm{m}}\right) \frac{d\left(i_{\mathrm{cir}}\right)}{d t} .
$$

4.3. HMC with One Six-Winding Coupled Inductor. Instead of using six inductances, one six-winding coupled inductor can be used to interconnect the VSC modules. Since the turn ratio of the coupled inductor is approximately $1: 1$, the selfinductances of all the windings are the same as shown in 


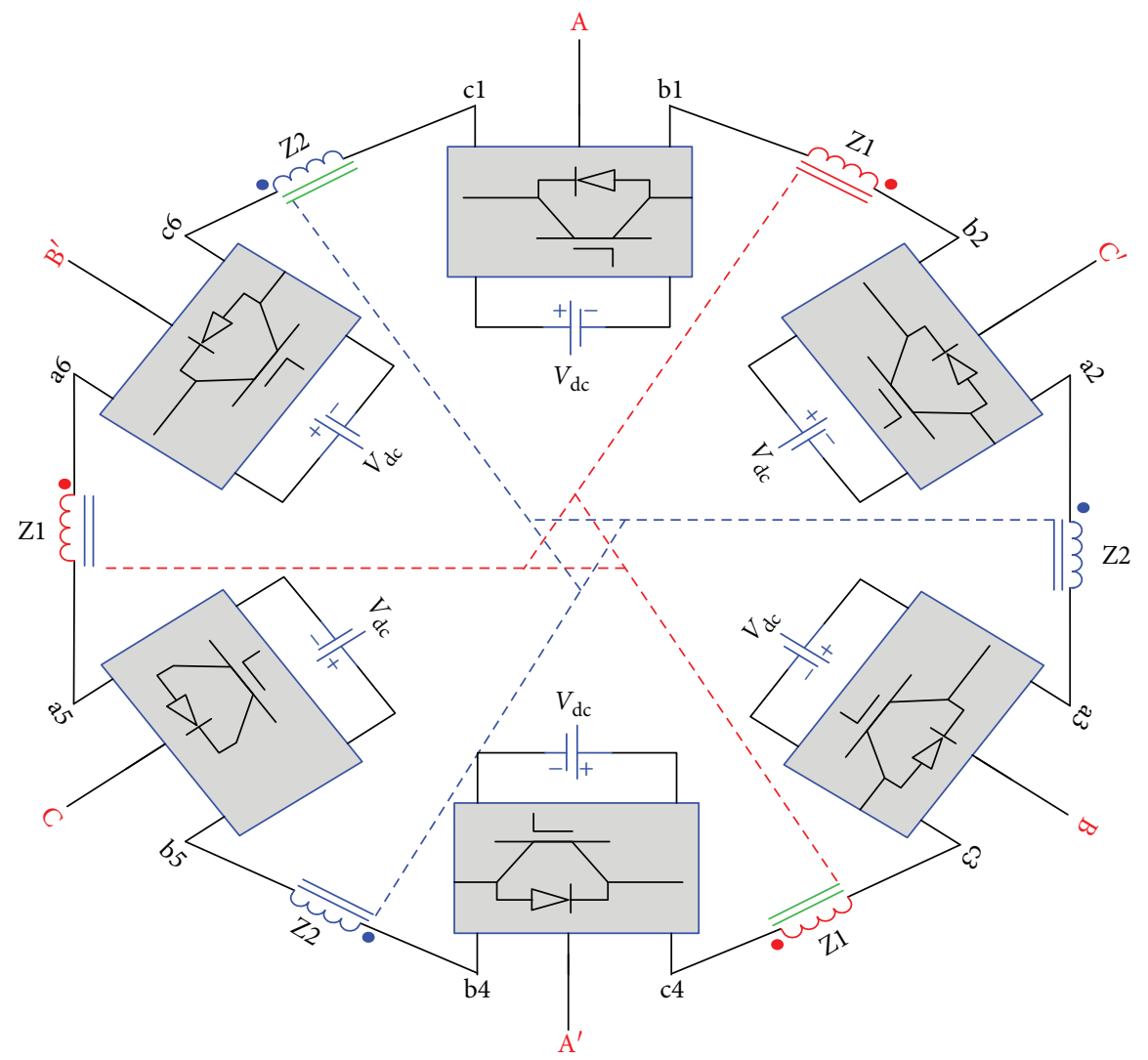

FIgURE 12: The HMC with two three-winding coupled inductors.

Figure 13. The HMC with one six-winding coupled inductor is shown in Figure 14. Applying the voltage equations of the coupled inductor, the following equations are given:

$$
\begin{aligned}
& v_{\mathrm{a} 5 \mathrm{a} 6}=L_{\mathrm{a}} \frac{d i_{\mathrm{a} 5}}{d t}+L_{\mathrm{m}} \frac{d i_{\mathrm{b} 1}+d i_{\mathrm{c} 3}+d i_{\mathrm{b} 5}+d i_{\mathrm{a} 3}+d i_{\mathrm{c} 1}}{d t}, \\
& v_{\mathrm{b} 1 \mathrm{~b} 2}=L_{\mathrm{b}} \frac{d i_{\mathrm{b} 1}}{d t}+L_{\mathrm{m}} \frac{d i_{\mathrm{a} 5}+d i_{\mathrm{c} 3}+d i_{\mathrm{b} 5}+d i_{\mathrm{a} 3}+d i_{\mathrm{c} 1}}{d t}, \\
& v_{\mathrm{c} 3 \mathrm{c} 4}=L_{\mathrm{c}} \frac{d i_{\mathrm{c} 3}}{d t}+L_{\mathrm{m}} \frac{d i_{\mathrm{a} 5}+d i_{\mathrm{b} 1}+d i_{\mathrm{b} 5}+d i_{\mathrm{a} 3}+d i_{\mathrm{c} 1}}{d t}, \\
& v_{\mathrm{a} 3 \mathrm{a} 2}=L_{\mathrm{a}} \frac{d i_{\mathrm{a} 3}}{d t}+L_{\mathrm{m}} \frac{d i_{\mathrm{b} 1}+d i_{\mathrm{c} 3}+d i_{\mathrm{b} 5}+d i_{\mathrm{a} 5}+d i_{\mathrm{c} 1}}{d t}, \\
& v_{\mathrm{b} 5 \mathrm{~b} 4}=L_{\mathrm{b}} \frac{d i_{\mathrm{b} 5}}{d t}+L_{\mathrm{m}} \frac{d i_{\mathrm{a} 5}+d i_{\mathrm{c} 3}+d i_{\mathrm{b} 1}+d i_{\mathrm{a} 3}+d i_{\mathrm{c} 1}}{d t}, \\
& v_{\mathrm{clc} 6}=L_{\mathrm{c}} \frac{d i_{\mathrm{c} 1}}{d t}+L_{\mathrm{m}} \frac{d i_{\mathrm{a} 5}+d i_{\mathrm{b} 1}+d i_{\mathrm{b} 5}+d i_{\mathrm{a} 3}+d i_{\mathrm{c} 3}}{d t} .
\end{aligned}
$$

Since,

$$
\begin{aligned}
& i_{\mathrm{a}}=i_{\mathrm{a} 5}=i_{\mathrm{a} 3}=i_{\mathrm{a} 1}=-i_{\mathrm{a} 2}=-i_{\mathrm{a} 4}=-i_{\mathrm{a} 6}, \\
& i_{\mathrm{b}}=i_{\mathrm{b} 5}=i_{\mathrm{b} 3}=i_{\mathrm{b} 1}=-i_{\mathrm{b} 2}=-i_{\mathrm{b} 4}=-i_{\mathrm{b} 6}, \\
& i_{\mathrm{c}}=i_{\mathrm{c} 5}=i_{\mathrm{c} 3}=i_{\mathrm{c} 1}=-i_{\mathrm{c} 2}=-i_{\mathrm{c} 4}=-i_{\mathrm{c} 6} .
\end{aligned}
$$

The voltage drop equations across each coupled inductor can be expressed as

$$
\begin{aligned}
& v_{\mathrm{a} 5 \mathrm{a} 6}=v_{\mathrm{a} 3 \mathrm{a} 2}=L_{\mathrm{a}} \frac{d i_{\mathrm{a}}}{d t}+L_{\mathrm{m}} \frac{d i_{\mathrm{a}}+2 d i_{\mathrm{b}}+2 d i_{\mathrm{c}}}{d t}, \\
& v_{\mathrm{b} 1 \mathrm{~b} 2}=v_{\mathrm{b} 5 \mathrm{~b} 4}=L_{\mathrm{b}} \frac{d i_{\mathrm{b}}}{d t}+L_{\mathrm{m}} \frac{d i_{\mathrm{b}}+2 d i_{\mathrm{a}}+2 d i_{\mathrm{c}}}{d t}, \\
& v_{\mathrm{c} 3 \mathrm{c} 4}=v_{\mathrm{clc6}}=L_{\mathrm{c}} \frac{d i_{\mathrm{b}}}{d t}+L_{\mathrm{m}} \frac{d i_{\mathrm{c}}+2 d i_{\mathrm{a}}+2 d i_{\mathrm{b}}}{d t},
\end{aligned}
$$

where

$$
L_{\mathrm{a}}=L_{\mathrm{b}}=L_{\mathrm{c}}=L+L_{\mathrm{m}}
$$

and

$$
\begin{aligned}
& i_{\mathrm{a}}=i_{\mathrm{a}}+i_{\text {cir }}, \\
& i_{\mathrm{b}}=i_{\mathrm{b}}+i_{\text {cir }}, \\
& i_{\mathrm{c}}=i_{\mathrm{c}}+i_{\text {cir }} .
\end{aligned}
$$

Using (34), the voltage drop across the coupled inductor can be expressed as

$$
\begin{aligned}
& v=v_{\mathrm{a} 5 \mathrm{a} 6}+v_{\mathrm{b} 1 \mathrm{~b} 2}+v_{\mathrm{c} 3 \mathrm{c} 4}+v_{\mathrm{a} 3 \mathrm{a} 2}+v_{\mathrm{b} 5 \mathrm{~b} 4}+v_{\mathrm{clc6}}, \\
& v=2 v_{\mathrm{a} 5 \mathrm{a} 6}+2 v_{\mathrm{b} 1 \mathrm{~b} 2}+2 v_{\mathrm{c} 3 \mathrm{c} 4}
\end{aligned}
$$




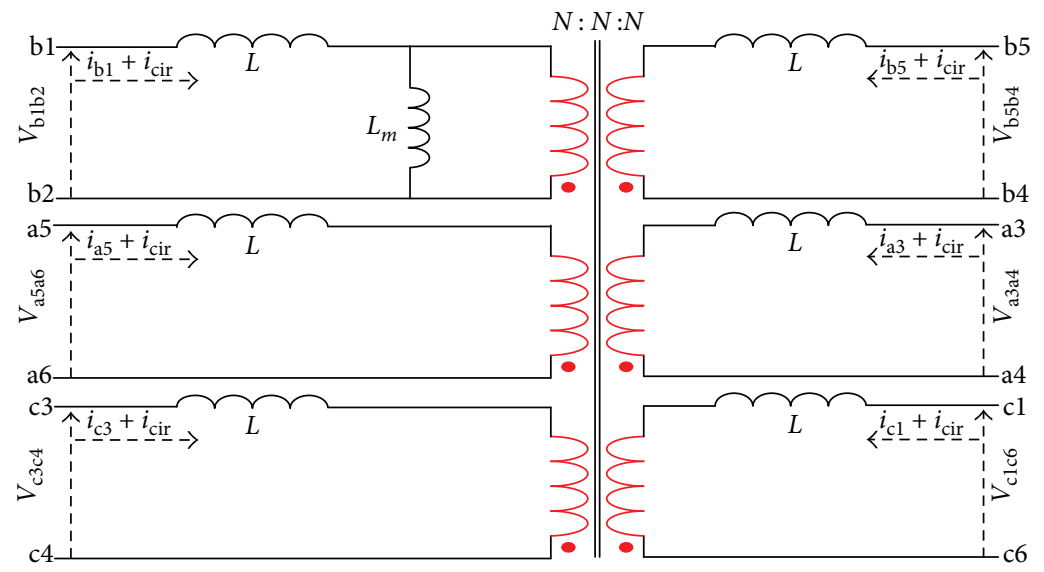

FIGURE 13: Equivalent circuit of the six-winding coupled inductor.

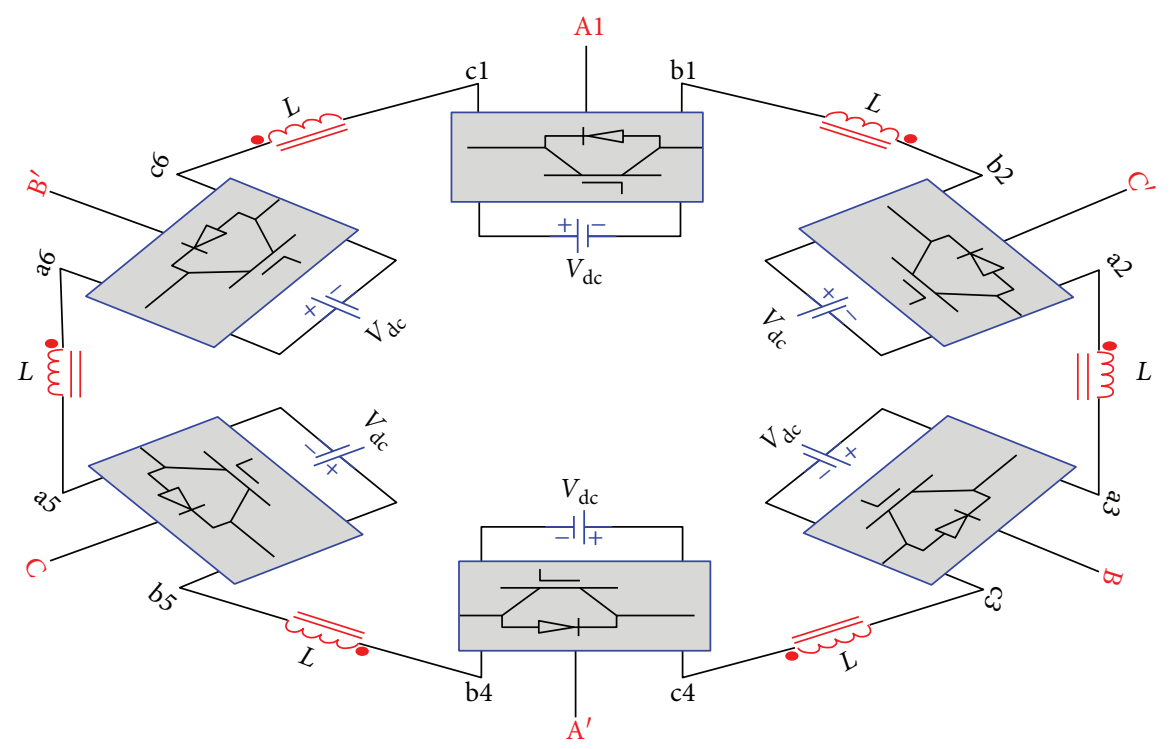

FIGURE 14: The HMC with one six-winding coupled inductor.

$v=\left(6 L+36 L_{\mathrm{m}}\right) \frac{d i_{\mathrm{cir}}}{d t}+\left(2 L+12 L_{\mathrm{m}}\right) \frac{d\left(i_{\mathrm{a}}+i_{\mathrm{b}}+i_{\mathrm{c}}\right)}{d t}$.

Under balanced conditions,

$$
i_{\mathrm{a}}+i_{\mathrm{b}}+i_{\mathrm{c}}=0
$$

Consequently, by applying (39) and (40), the voltage drop on the coupled inductor windings is

$$
v=\left(6 L+36 L_{\mathrm{m}}\right) \frac{d i_{\mathrm{cir}}}{d t} .
$$

It is considered that the magnetizing inductance is much higher than the leakage inductance. Therefore, neglecting the leakage inductance, the two-winding coupled inductor imposes twelve times the magnetizing inductance for the circulating current, while the impedance to the circulating current using three-winding coupled inductors is eighteen as much as the magnetizing inductance. Thanks to the six-winding coupled inductor, the impedance on the circulating current path is thirty six times the magnetizing inductance.

In a general way if $k$ is the number of the coupled inductor windings, the impedance to the circulating current can be expressed as

$$
Z_{\text {cir }}=2 \pi f\left(6 k L_{\mathrm{m}}\right)
$$

\section{Control Scheme and Modulation Strategy}

5.1. Control Scheme. The main function of the controller is to generate reference currents such that the proposed converter only provides available active power from the DC links to the grid at the point of common coupling (PCC) $[22,23]$. Using the equivalent circuit model presented in 


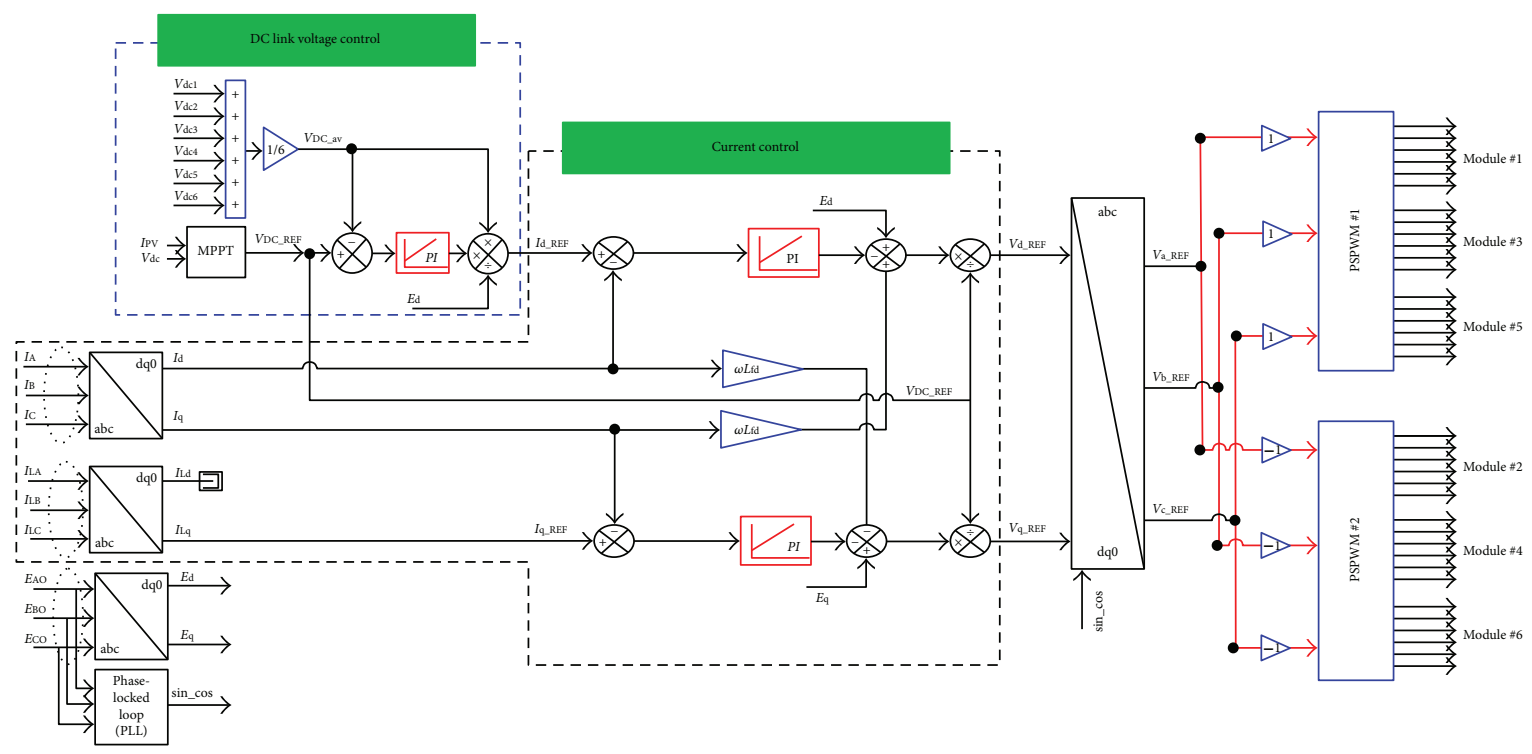

FIGURE 15: HMC control block diagram.

Figure 7 and applying Kirchhoff's voltage and current laws at the PCC, the following two equations in the abc frame can be obtained:

$$
\begin{gathered}
{\left[\begin{array}{c}
E_{\mathrm{AO}^{\prime}} \\
E_{\mathrm{BO}^{\prime}} \\
E_{\mathrm{CO}^{\prime}}
\end{array}\right]=\left[\begin{array}{c}
\overline{U_{\mathrm{AO}}} \\
\overline{U_{\mathrm{BO}}} \\
\overline{U_{\mathrm{CO}}}
\end{array}\right]+L_{\mathrm{fd}} \frac{d}{d t}\left[\begin{array}{c}
I_{\mathrm{A}} \\
I_{\mathrm{B}} \\
I_{\mathrm{C}}
\end{array}\right]+U_{\mathrm{O}^{\prime} \mathrm{O}}} \\
C_{\mathrm{eq}} \frac{d U_{\mathrm{DC} \_\mathrm{av}}}{d t}=\left[S_{\mathrm{A}} S_{\mathrm{B}} S_{\mathrm{C}}\right]\left[\begin{array}{c}
I_{\mathrm{A}} \\
I_{\mathrm{B}} \\
I_{\mathrm{C}}
\end{array}\right],
\end{gathered}
$$

where $L_{\mathrm{fd}}=L_{\mathrm{f}}+L_{\mathrm{d}}$ is the equivalent interface inductor and $S_{\mathrm{A}}, S_{\mathrm{B}}$, and $S_{\mathrm{C}}$ represent the switching states of the equivalent circuit model under balanced conditions.

Assuming that the voltages are balanced and the zerosequence component is zero, the voltage between the neutral virtual point of equivalent circuit model $(\mathrm{O})$ and the grid neutral point $\left(\mathrm{O}^{\prime}\right)$ is given by

$$
\begin{aligned}
& U_{\mathrm{O}^{\prime} \mathrm{O}}=-\frac{\left(\overline{U_{\mathrm{AO}}}+\overline{U_{\mathrm{BO}}}+\overline{U_{\mathrm{CO}}}\right)}{3}, \\
& {\left[\begin{array}{c}
\overline{U_{\mathrm{AO}}} \\
\overline{U_{\mathrm{BO}}} \\
\overline{U_{\mathrm{CO}}}
\end{array}\right]=U_{\mathrm{DC} \_\mathrm{av}}\left[\begin{array}{l}
S_{\mathrm{A}} \\
S_{\mathrm{B}} \\
S_{\mathrm{C}}
\end{array}\right] .}
\end{aligned}
$$

Substituting (46) into (43) and (44), the following relation is obtained:

$$
\begin{aligned}
\frac{d}{d t}\left[\begin{array}{c}
I_{\mathrm{A}} \\
I_{\mathrm{B}} \\
I_{\mathrm{C}}
\end{array}\right]= & \frac{1}{L_{\mathrm{fd}}}\left[\begin{array}{c}
E_{\mathrm{AO}^{\prime}} \\
E_{\mathrm{BO}^{\prime}} \\
E_{\mathrm{CO}^{\prime}}
\end{array}\right] \\
& -\frac{U_{\mathrm{DC}_{\mathrm{av}}}}{L_{\mathrm{fd}}}\left(\left[\begin{array}{l}
S_{\mathrm{A}} \\
S_{\mathrm{B}} \\
S_{\mathrm{C}}
\end{array}\right]-\frac{1}{3}\left[\begin{array}{lll}
S_{\mathrm{A}} & S_{\mathrm{B}} & S_{\mathrm{C}}
\end{array}\right]\left[\begin{array}{l}
1 \\
1 \\
1
\end{array}\right]\right) .
\end{aligned}
$$

The dynamic model in the abc frame of the HMC equivalent circuit is represented by (47). The switching state functions, $d_{i}(i=\mathrm{A}, \mathrm{B}, \mathrm{C})$, are defined as

$$
\left[\begin{array}{l}
d_{\mathrm{A}} \\
d_{\mathrm{B}} \\
d_{\mathrm{C}}
\end{array}\right]=\left(\left[\begin{array}{l}
S_{\mathrm{A}} \\
S_{\mathrm{B}} \\
S_{\mathrm{C}}
\end{array}\right]-\frac{1}{3}\left[\begin{array}{lll}
S_{\mathrm{A}} & S_{\mathrm{B}} & S_{\mathrm{C}}
\end{array}\right]\left[\begin{array}{l}
1 \\
1 \\
1
\end{array}\right]\right) .
$$

The dynamic model of the equivalent circuit model in the abc frame is achieved by combining (47) and (48) in the following equation:

$$
L_{\mathrm{fd}} \frac{d}{d t}\left[\begin{array}{c}
I_{\mathrm{A}} \\
I_{\mathrm{B}} \\
I_{\mathrm{C}}
\end{array}\right]=\left[\begin{array}{c}
E_{\mathrm{AO}^{\prime}} \\
E_{\mathrm{BO}^{\prime}} \\
E_{\mathrm{CO}^{\prime}}
\end{array}\right]-U_{\mathrm{DC}_{\mathrm{av}}}\left[\begin{array}{c}
d_{\mathrm{A}} \\
d_{\mathrm{B}} \\
d_{\mathrm{C}}
\end{array}\right] .
$$

The DC side differential equation can be written as

$$
\frac{d U_{\mathrm{DC} \_\mathrm{av}}}{d t}=\frac{1}{C_{\mathrm{eq}}} I_{\mathrm{dc}}=\left[\begin{array}{lll}
d_{\mathrm{A}} & d_{\mathrm{B}} & d_{\mathrm{C}}
\end{array}\right]\left[\begin{array}{c}
I_{\mathrm{A}} \\
I_{\mathrm{B}} \\
I_{\mathrm{C}}
\end{array}\right],
$$




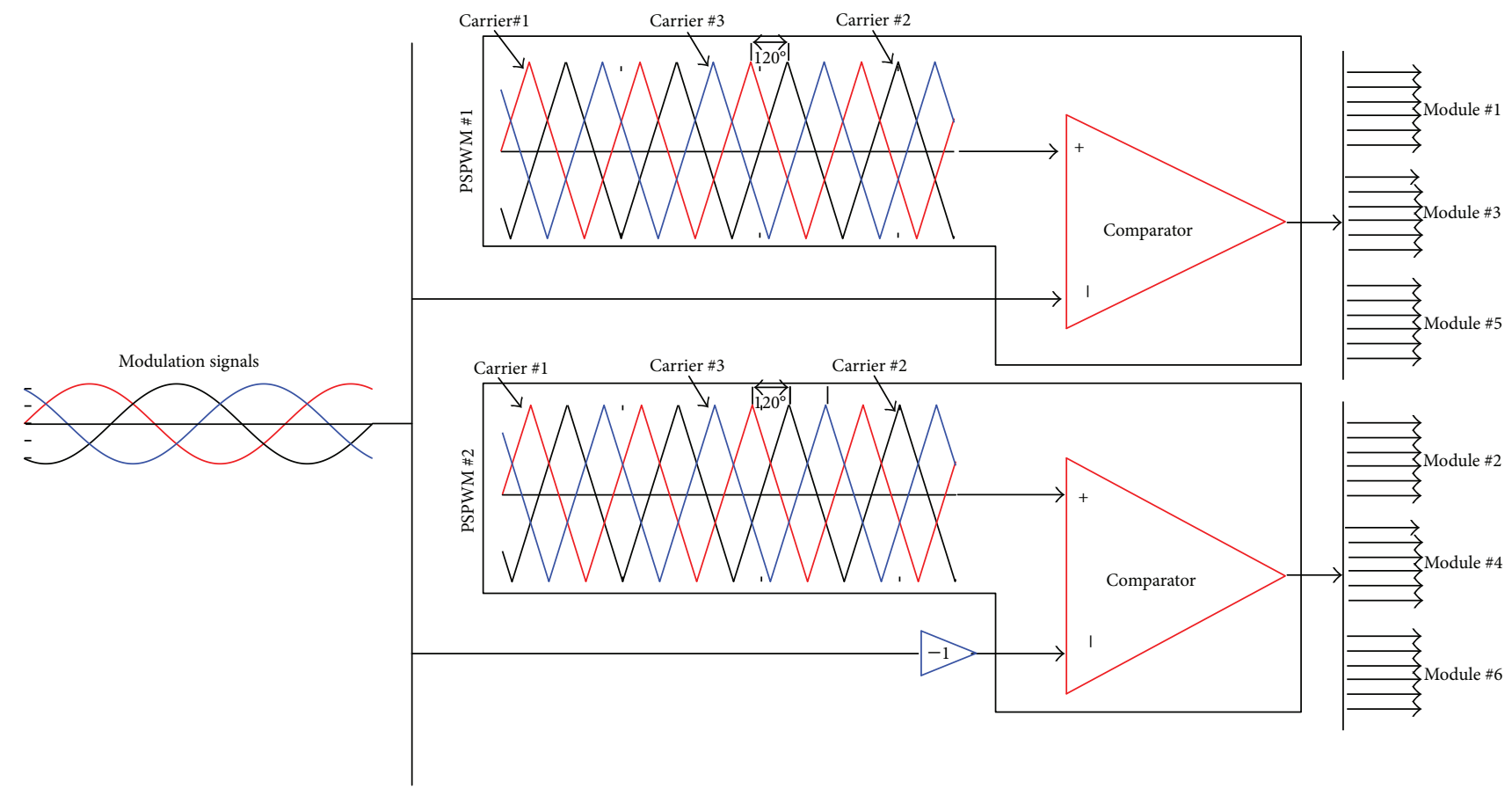

Figure 16: Proposed PS-PWM diagram.

$$
\frac{d U_{\mathrm{DC} \_\mathrm{av}}}{d t}=\frac{1}{C_{\mathrm{eq}}}\left(2 d_{\mathrm{A}}+d_{\mathrm{B}}\right) I_{\mathrm{A}}+\frac{1}{C_{\mathrm{eq}}}\left(d_{\mathrm{A}}+2 d_{\mathrm{B}}\right) I_{\mathrm{B}} .
$$

It can be seen that the model represented by (49) and (51) is time varying. Thus, to facilitate the control algorithm implementation, the model can be expressed in the synchronous reference frame rotating at constant frequency $\omega$. The corresponding conversion matrix is

$$
C_{\mathrm{dq}}^{\mathrm{abc}}=\sqrt{\frac{2}{3}}\left[\begin{array}{ccc}
\cos \theta & \cos \left(\theta-2 \frac{\pi}{3}\right) & \cos \left(\theta-4 \frac{\pi}{3}\right) \\
-\sin \theta & -\sin \left(\theta-2 \frac{\pi}{3}\right) & -\sin \left(\theta-4 \frac{\pi}{3}\right)
\end{array}\right],
$$

where $\theta=\omega t$.

Applying the coordinate transformation to (49) we obtain

$$
L_{\mathrm{fd}} \frac{d}{d t}\left[\begin{array}{c}
I_{\mathrm{d}} \\
I_{\mathrm{q}}
\end{array}\right]=\left[\begin{array}{c}
E_{\mathrm{d}} \\
E_{\mathrm{q}}
\end{array}\right]+L_{\mathrm{f}} \omega\left[\begin{array}{c}
I_{\mathrm{q}} \\
-I_{\mathrm{d}}
\end{array}\right]-U_{\mathrm{DC}_{\mathrm{av}}}\left[\begin{array}{c}
d_{\mathrm{d}} \\
d_{\mathrm{q}}
\end{array}\right] .
$$

Similarly, applying this transformation to (50) we obtain

$$
C_{\mathrm{eq}} \frac{d U_{\mathrm{DC}_{-} \mathrm{av}}}{d t}=d_{\mathrm{d}} I_{\mathrm{d}}+d_{\mathrm{q}} I_{\mathrm{q}} .
$$

The obtained model, represented by (53) and (54), is nonlinear owing to the product between the state variables (i.e., $I_{\mathrm{d}}, I_{\mathrm{q}}$, and $U_{\text {DC_av }}$ ) and the inputs (i.e., $d_{\mathrm{d}}$ and $d_{\mathrm{q}}$ ).

Figure 11 shows the control principle of the HMC. Because the proposed configuration is a three-wire system, only two phase currents are required to be measured.
TABLE 2: General data of the proposed system.

\begin{tabular}{lc}
\hline Parameter & Value \\
\hline $\begin{array}{l}\text { System parameters } \\
\text { Nominal power }\end{array}$ & $P=2.5 \mathrm{kVA}$ \\
Phase voltage and frequency & $V_{\mathrm{ph}}=110 \mathrm{~V}(\mathrm{rms}), f_{\mathrm{sys}}=50 \mathrm{~Hz}$, \\
& $f_{\text {swiching }}=2500 \mathrm{~Hz}$ \\
Output current & $I_{\mathrm{out}}=8.8 \mathrm{~A}(\mathrm{rms})$ \\
DC bus voltages & $V_{\mathrm{dc} 1}=V_{\mathrm{dc} 2}=V_{\mathrm{dc} 3}=V_{\mathrm{dc} 4}$ \\
& $=V_{\mathrm{dc5}}=V_{\mathrm{dc} 6}=52.6 \mathrm{~V}$ \\
Open-end winding transformers & $V_{\mathrm{pri}} / V_{\mathrm{sec}}=1, f_{\mathrm{tran}}=50 \mathrm{~Hz}$ \\
Current controller parameters & $K_{\mathrm{p}}=55, K_{\mathrm{i}}=0.001$ \\
Voltage controller parameters & $K_{\mathrm{p}}=3, K_{i}=20$ \\
\hline Coupled inductor parameters & \\
RMS voltage, current & $20 \mathrm{~V}(\mathrm{rms}), 8.8 \mathrm{~A}(\mathrm{rms})$ \\
Magnetizing inductance & $3.2 \mathrm{mH}$ \\
Leakage inductance & $150 \mu \mathrm{H}$ \\
\hline
\end{tabular}

Currents $I_{\mathrm{A}}$ and $I_{\mathrm{B}}$ are measured and converted to the dq0 frame to obtain the corresponding currents $I_{\mathrm{d}}$ and $I_{\mathrm{q}}$. Accordingly, (53) is rewritten as follows:

$$
L_{\mathrm{fd}}\left[\begin{array}{c}
u_{\mathrm{d}} \\
u_{\mathrm{q}}
\end{array}\right]=\left[\begin{array}{c}
E_{\mathrm{d}} \\
E_{\mathrm{q}}
\end{array}\right]+L_{\mathrm{fd}} \omega\left[\begin{array}{c}
I_{\mathrm{q}} \\
-I_{\mathrm{d}}
\end{array}\right]-U_{\mathrm{DC}_{\mathrm{av}}}\left[\begin{array}{c}
d_{\mathrm{d}} \\
d_{\mathrm{q}}
\end{array}\right],
$$

where $\left[\begin{array}{l}u_{\mathrm{d}} \\ u_{\mathrm{q}}\end{array}\right]=(d / \mathrm{d} t)\left[\begin{array}{c}I_{\mathrm{d}} \\ I_{\mathrm{q}}\end{array}\right]$ 


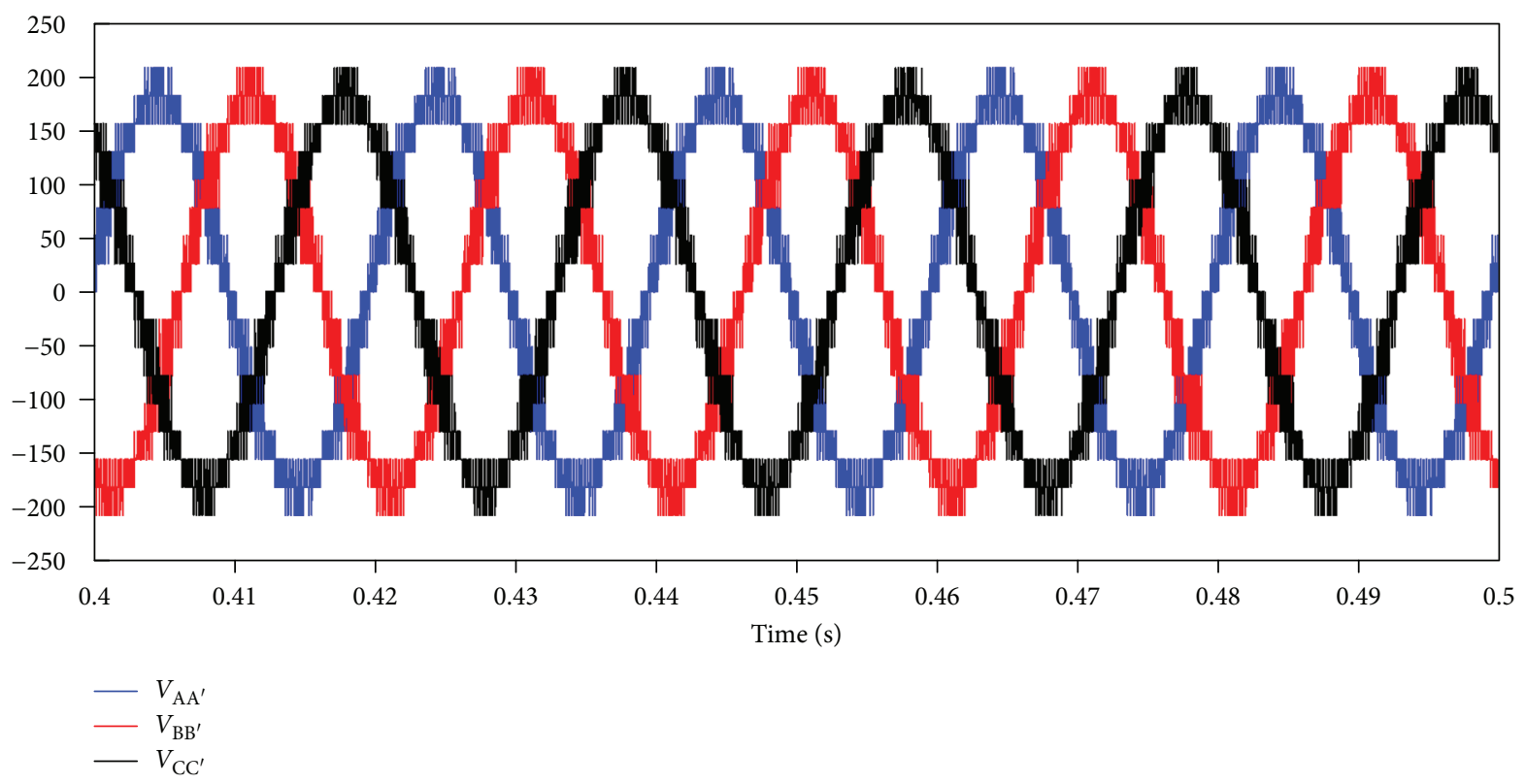

FIgURE 17: Three-phase output voltage of the HMC.
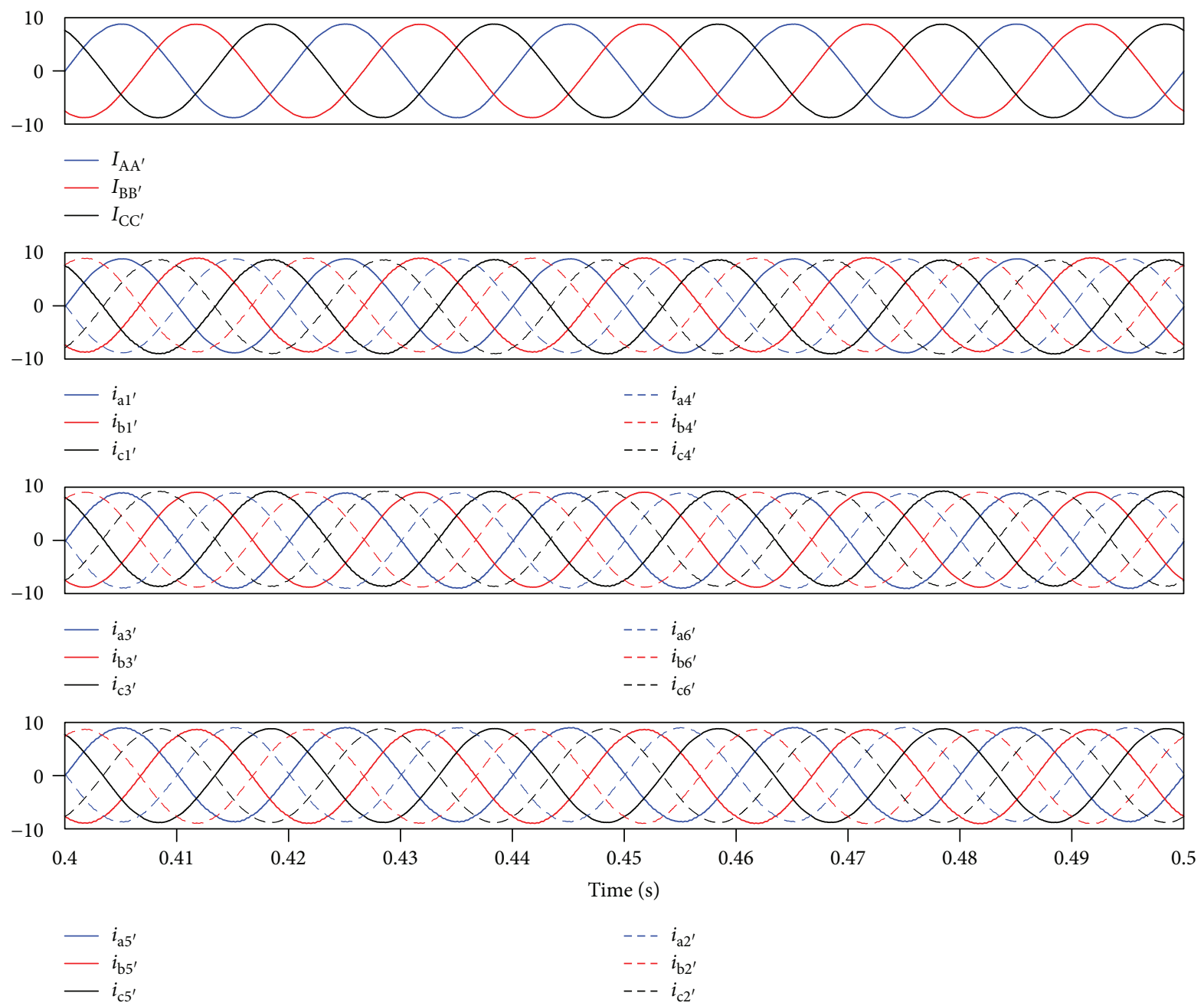

FIgURE 18: Currents inside the HMC. 


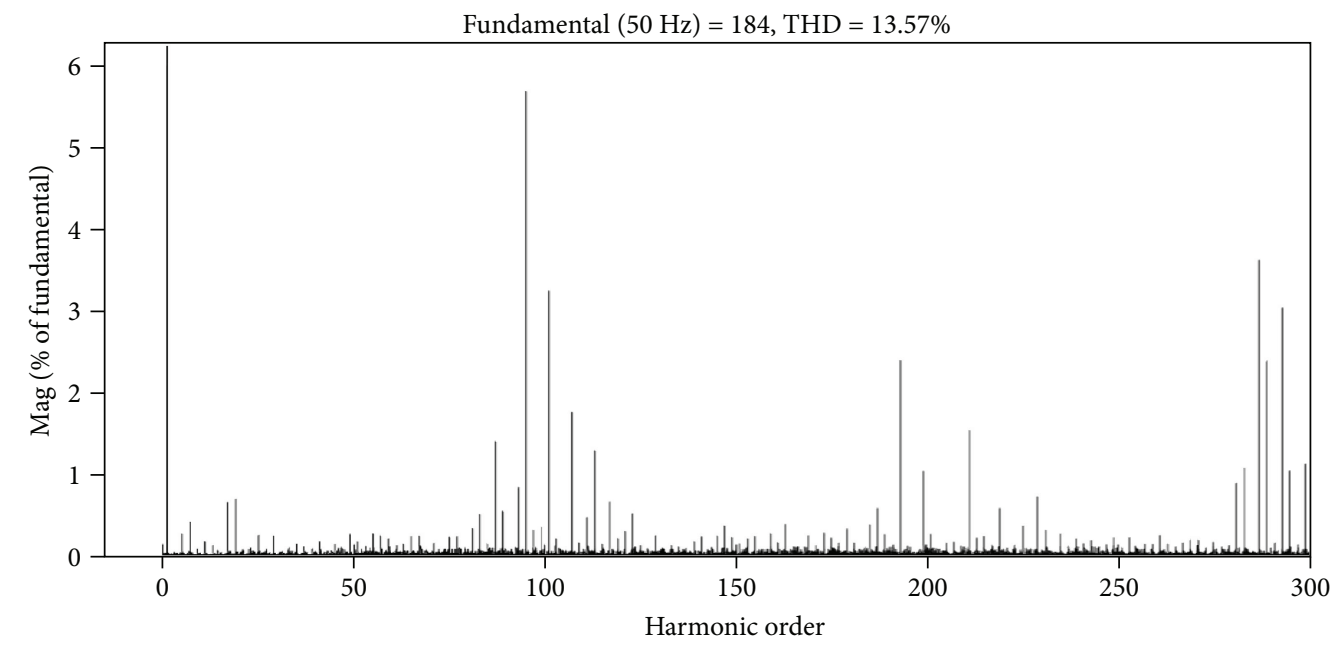

Figure 19: THD of the HMC output voltage.

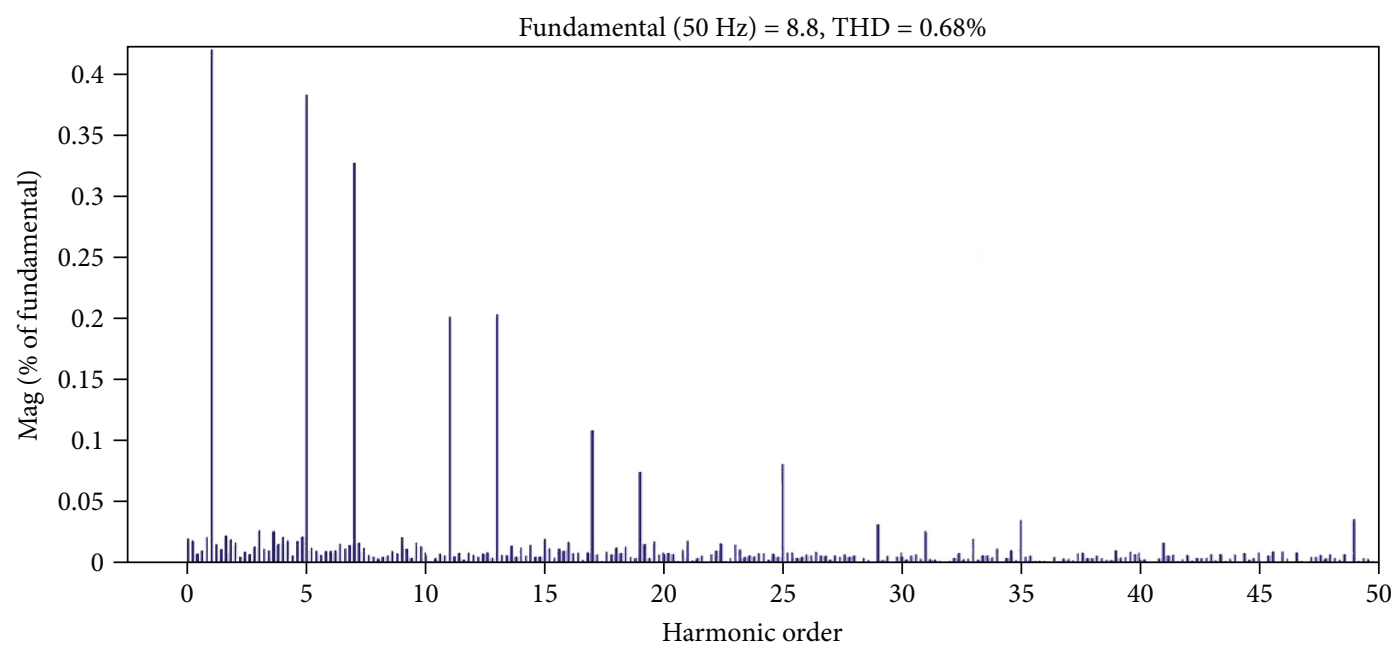

Figure 20: THD of the HMC output current.

Demonstrated that currents $I_{\mathrm{d}}$ and $I_{\mathrm{q}}$ can be controlled separately by acting on inputs $u_{\mathrm{d}}$ and $u_{\mathrm{q}}$, respectively. Hence, the controller is designed using the following expressions:

$$
\begin{aligned}
& u_{\mathrm{d}}=k_{\mathrm{p}} \tilde{i_{\mathrm{d}}}+k_{\mathrm{i}} \int \tilde{i_{\mathrm{d}}} d t, \\
& u_{\mathrm{q}}=k_{\mathrm{p}} \tilde{i_{\mathrm{q}}}+k_{\mathrm{i}} \int \tilde{i_{\mathrm{q}}} d t,
\end{aligned}
$$

where $\tilde{i_{\mathrm{d}}}=I_{\mathrm{d} \_ \text {REF }}-I_{\mathrm{d}}$ and $\tilde{i_{\mathrm{q}}}=I_{\mathrm{q} \_ \text {REF }}-I_{\mathrm{q}}$ are the current error signals, with $I_{\mathrm{d} \_ \text {REF }}$ and $I_{\mathrm{q}-\text { REF }}$ being the reference values for currents $I_{\mathrm{d}}$ and $I_{\mathrm{q}}$, respectively.

Using (55), the current control law is given by the following expression: $\left[\begin{array}{l}d_{\mathrm{d}} \\ d_{\mathrm{q}}\end{array}\right]=\frac{L_{\mathrm{fd}} \omega}{U_{\text {DC_av }}}\left[\begin{array}{c}I_{\mathrm{q}} \\ -I_{\mathrm{d}}\end{array}\right]+\frac{1}{U_{\text {DC_av }}}\left[\begin{array}{c}E_{\mathrm{d}} \\ E_{\mathrm{q}}\end{array}\right]-\frac{L_{\mathrm{fd}}}{U_{\mathrm{DC}_{\mathrm{av}}}}\left[\begin{array}{c}u_{\mathrm{d}} \\ u_{\mathrm{q}}\end{array}\right]$.

The $d$-axis reference current $\left(I_{\mathrm{d}_{-} \mathrm{REF}}\right)$ is produced using the DC-link voltage controller, while the $q$-axis reference current $\left(I_{\mathrm{q}-\mathrm{REF}}\right)$ is taken as the load $q$-axis current $\left(I_{\mathrm{Lq}}\right)$. To aim for a unity power factor, the $I_{\mathrm{q}_{-} \mathrm{REF}}$ is set to zero (i.e., $i_{\mathrm{q}-\mathrm{REF}}=0$ ). The active power exchange between the DC links and the grid is proportional to the direct-axis current $I_{\mathrm{d}}$ and can be expressed as

$$
P_{\mathrm{dc}}=\frac{3}{2}\left(E_{\mathrm{d}} I_{\mathrm{d}}+E_{\mathrm{q}} I_{\mathrm{q}}\right)=\frac{3}{2} E_{\mathrm{d}} I_{\mathrm{d}}
$$


(58) it is shown that direct-axis current $I_{\mathrm{d}}$ is responsible for maintaining the DC-link voltages at a desired value. Thus, using (54), one deduces that

$$
C_{\text {eq }} \frac{d U_{\text {DC_av }}}{d t}=d_{\mathrm{d}} I_{\mathrm{d}}=u_{\mathrm{dc}} .
$$

Consequently, the active current is

$$
I_{\mathrm{d}}=\frac{u_{\mathrm{dc}}}{d_{\mathrm{d}}}=\frac{u_{\mathrm{dc}} V_{\text {DC_av }}}{d_{\mathrm{d}} V_{\text {DC_av }}} .
$$

Assuming that the current loop is perfect and the HMC works under balanced conditions, the following expressions hold:

$$
\begin{aligned}
d_{\mathrm{d}} V_{\mathrm{DC} \_\mathrm{av}} & =E_{\mathrm{d}}, \\
I_{\mathrm{d}} & =\frac{u_{\mathrm{dc}}}{d_{\mathrm{d}}}=\frac{u_{\mathrm{dc}} V_{\mathrm{DC} \_\mathrm{av}}}{E_{\mathrm{d}}}, \\
{\left[\begin{array}{c}
E_{\mathrm{d}} \\
E_{\mathrm{q}}
\end{array}\right] } & =\sqrt{\frac{3}{2}}\left[\begin{array}{l}
\widehat{V} \\
0
\end{array}\right],
\end{aligned}
$$

where $\widehat{V}$ and $E_{\mathrm{d}}$ are the RMS voltage and the direct-axis phase voltage at the PCC, respectively. Thus, the control effort of the DC link voltage loop is given by

$$
I_{\mathrm{d} \_ \text {REF }}=\frac{u_{\mathrm{dc}}}{d_{\mathrm{d}}}=\sqrt{\frac{2}{3}} \frac{V_{\mathrm{DC} \_\mathrm{av}}}{\widehat{V}} u_{\mathrm{dc}} .
$$

To control the DC-link voltage, a PI controller is used, which is expressed as

$$
u_{\mathrm{dc}}=k_{\mathrm{pdc}} \widetilde{v_{\mathrm{dc}}}+k_{\mathrm{idc}} \int \widetilde{v_{\mathrm{dc}}} d t
$$

where $\widetilde{v_{\mathrm{dc}}}=V_{\mathrm{DC} \_\mathrm{REF}}-V_{\mathrm{DC} \_ \text {av }}$ is the DC-link voltage error, whereas $V_{\text {DC_REF }}$ and $V_{\text {DC_av }}$ are the DC-link reference and average voltages, respectively.

5.2. DC-Link Voltage Controller. With reference to Figure 3, the HMC is based on a symmetric configuration, having six converters with identical power capabilities that are supplied by six equal PV strings. The PV strings are directly connected to each converter, $V_{\mathrm{pv} 1}=V_{\mathrm{pv} 2}=V_{\mathrm{pv} 3}=V_{\mathrm{pv} 4}=$ $V_{\mathrm{pv} 5}=V_{\mathrm{pv} 6}=V_{\mathrm{pv}}$, the MPPT must be achieved by the converters, and the DC-link voltages continuously fluctuate. Because the PV strings are supposed to be identical, being created by a single PV string divided into six identical parts, a single MPPT algorithm can be considered. For this reason, the same DC-link voltage reference for the six converters has been considered. The DC-link voltage reference is compared to the sum of the actual six DC-link voltages, and the error is passed through a PI controller to determine the control parameter $u_{\mathrm{dc}}$.

5.3. Modulation Strategy. To obtain an output voltage with low total harmonic distortion (THD), a multicarrier phaseshifted PWM (PS-PWM) switching strategy [24, 25] is implemented to drive each IGBT in the HMC. Optimum harmonic cancellation is accomplished by shifting each carrier

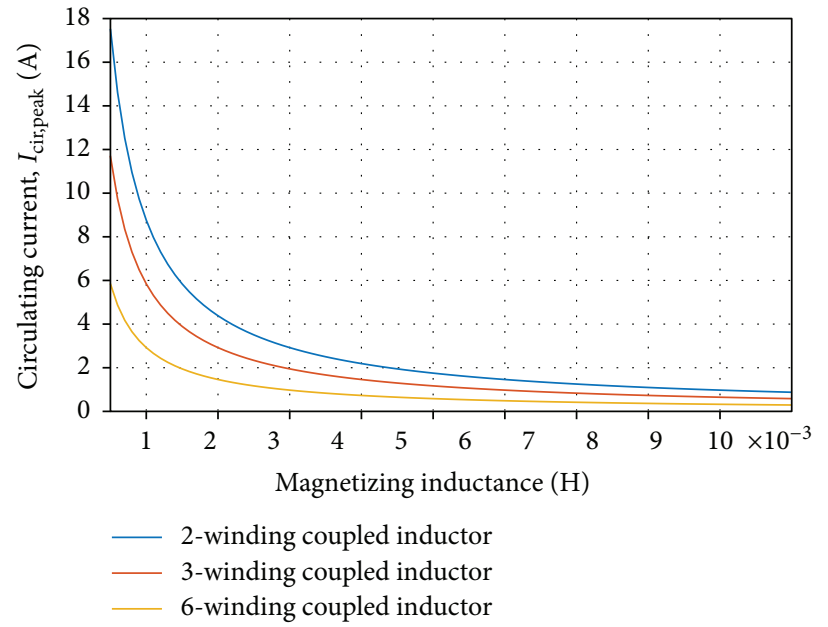

FIGURE 21: Peak circulating current versus magnetizing inductance.

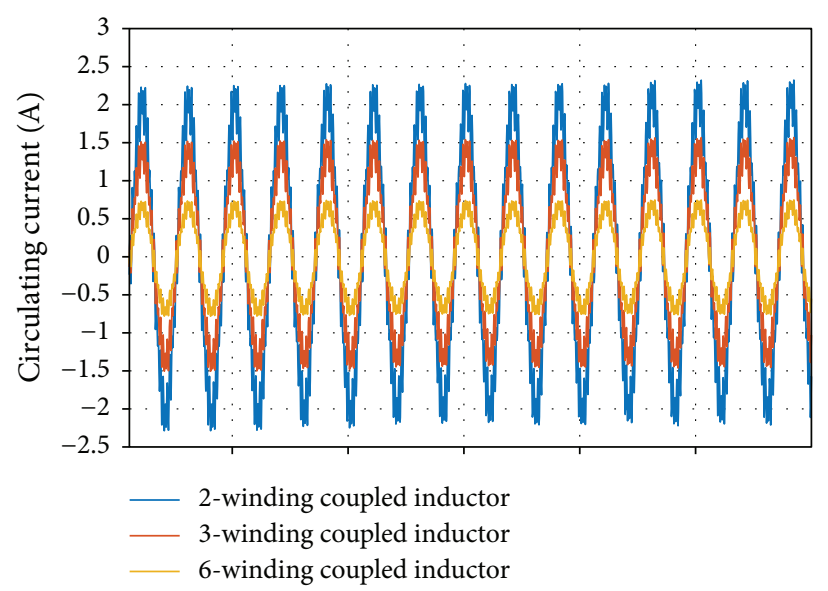

FIGURE 22: Circulating current inside the HMC with multiwinding coupled inductors.

cell by $2 \pi T_{\mathrm{s}} / 3 T$ in sequence, where $T_{\mathrm{s}}$ is the switching time and $T$ is the cycle modulation time. A reference signal of $50 \mathrm{~Hz}$ is generated using the control algorithm represented in Figure 15, with the switching frequency fixed at $2500 \mathrm{~Hz}$.

Figure 16 shows the relationship between the modulation waveforms and the three groups of carriers within the HMC. As shown in Figure 16, triangular carriers (i.e., carrier \#1, carrier $\# 2$, and carrier \#3) are phase-shifted $120^{\circ}$ to each other and directly compared with the modulation signals to drive the IGBTs within module \#1, module \#2, and module \#3. In order to generate the switching signals used to drive the IGBTs within module \#2, module \#4, and module \#6, the modulation signals are inverted and then compared with the triangular carriers.

\section{Simulation Results}

In order to demonstrate the performance of the HMC and its control algorithm, the complete grid-connected PV system 
2-winding coupled inductor
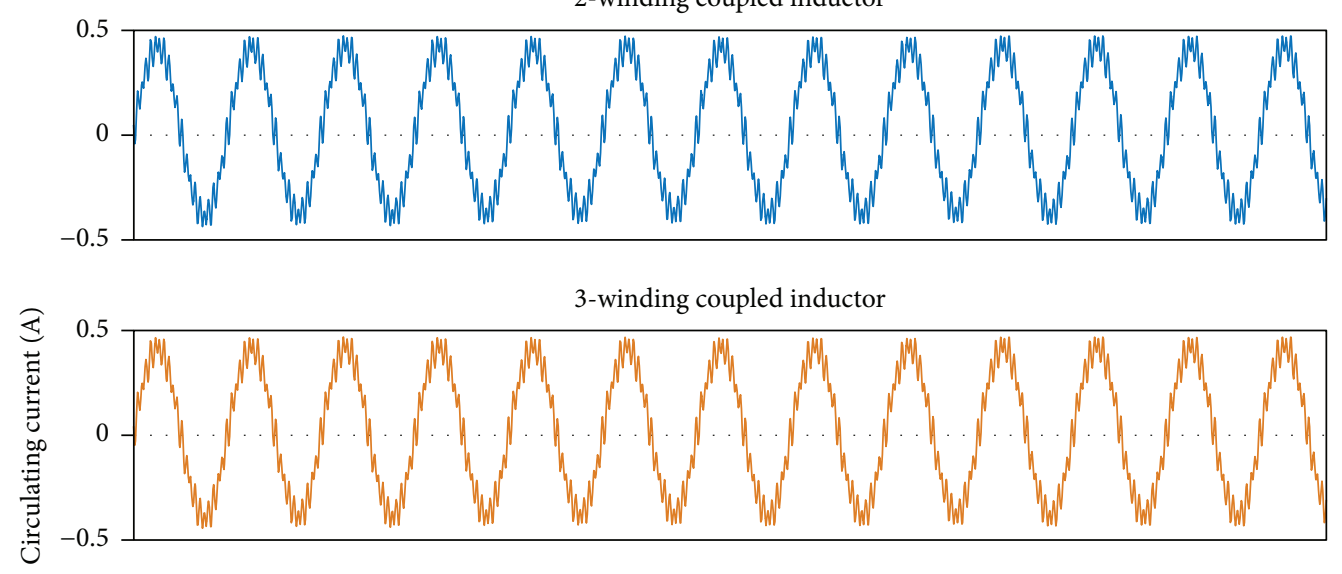

6-winding coupled inductor

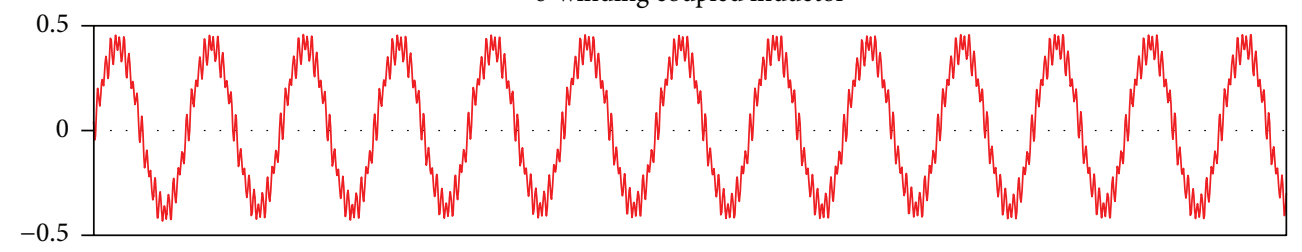

FIGURE 23: Circulating current inside the HMC.

was simulated using the MATLAB/Simulink environment. The technical characteristics of the system parameters and the coupled inductors are provided in Table 2. In order to validate the performance of the HMC, a PS-PWM technique has been implemented, as shown in Figure 16. The output active and reactive power supplies in response to the fluctuations in solar radiation value are shown in the following subsections.

6.1. Performance Analysis. The seventeen-level phase voltages of the HMC are generated at the steady state and shown in Figure 17. It can be seen that the voltages are balanced, as shown in the voltage phasor diagram. Figure 18 demonstrates the currents of modules 1,3 , and 5, and the currents of modules 2, 4, and 6. Given the configuration of the three-phase HMC, the line currents of every VSC module within the HMC are symmetrical, hence verifying the relationship in (5).

From this figure, it can also be acknowledged that the direction of the currents of modules 2, 4, and 6 is reversed from those of modules 1, 3, and 5. Moreover, the currents inside every VSC module within the HMC are the same as the output currents.

The THD values of the output voltage and current are calculated using the following equation.

$$
\% \text { THD }_{x}=100 \sqrt{\sum_{h \neq 1}\left(\frac{x_{\mathrm{sh}}}{x_{\mathrm{s} 1}}\right)^{2}},
$$

where the subscript $x$ indicates the THD in the signal (voltage or current), $x_{\mathrm{s} 1}$ is the fundamental component, $x_{\mathrm{sh}}$ is the component at the $h$ harmonic frequency.

The harmonic spectra of the output voltage and current are shown in Figures 19 and 20, respectively. The THD of the HMC current is $0.68 \%$, which is fewer than $5 \%$ and meets the power quality standard. Using the suggested modulation technique, the highest harmonic family of the phase voltage appears at the band of the 100th harmonic order. Consequently, the effective switching frequency of the phase voltage is two times higher than the switching frequency.

As a comparison, the HMC using two-, three-, and sixwinding coupled inductors are simulated under the conditions. The magnetizing inductance of each coupled inductor is $3.5 \mathrm{mH}$. According to the current from the equations provided in Section 4, if the voltage of the DC links is unbalanced the circulating current will be introduced on the converter output currents. Therefore, to intentionally produce a circulating current, the DC link voltage of Module 3 is decreased from 52.6 to $26.3 \mathrm{~V}$. The created loop voltage is computed using the following equation:

$$
V_{\text {loop,rms }}=\frac{\sqrt{3}}{2 \sqrt{2}}(52.6-26.3) m_{\mathrm{a}} .
$$

Thus, using (42) and (65), the circulating current inside the HMC is expressed as

$$
I_{\text {cir,peak }}=\frac{\sqrt{3}}{24 \pi}(52.6-26.3) \frac{m_{\mathrm{a}}}{f k L_{\mathrm{m}}} .
$$

Investigations with different magnetizing inductance levels have been carried. Figure 21 shows the theoretical values of the peak circulating currents with different magnetizing inductance levels. Figure 22 shows the simulation results with a relatively large magnetizing inductance $(3.5 \mathrm{mH})$. The circulating currents are found by measuring the difference between the output currents of module 1 and module 3. As shown in the waveforms, the circulating 


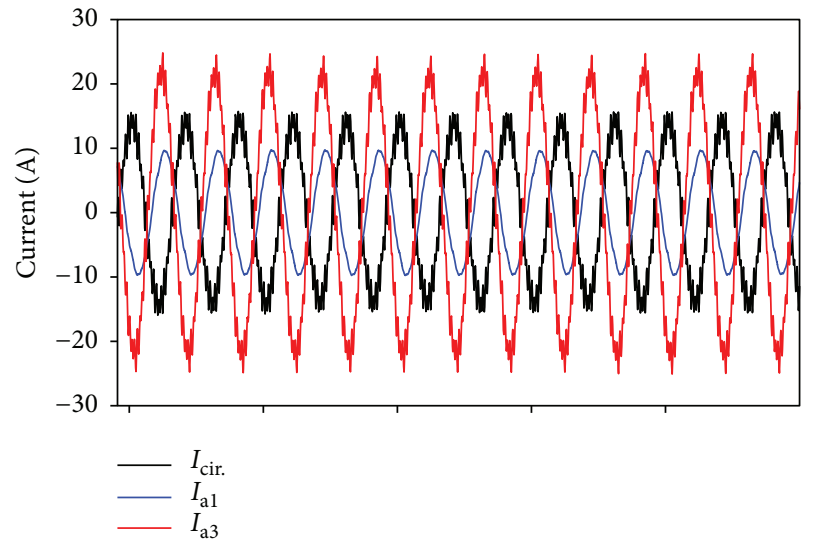

FIGURE 24: Circulating current with two-winding coupled inductors with a magnetizing inductance of $0.5 \mathrm{mH}$.

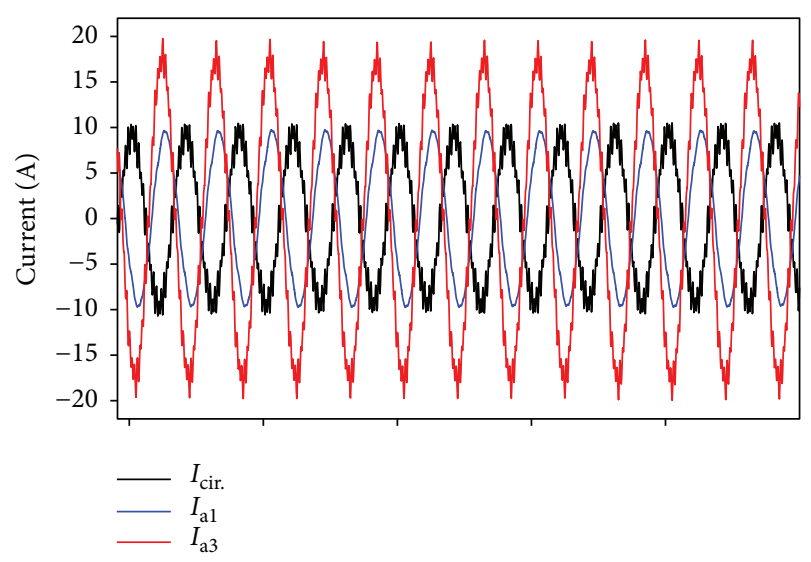

FIGURE 25: Circulating current with three-winding coupled inductors with a magnetizing inductance of $0.5 \mathrm{mH}$.

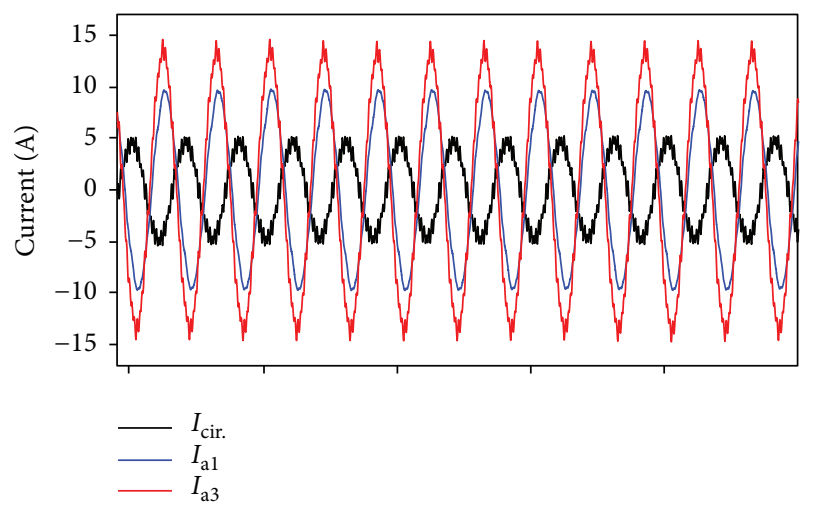

FIGURE 26: Circulating current with six-winding coupled inductors with a magnetizing inductance of $0.5 \mathrm{mH}$.

currents inside the HMC with two-, three-, and six-winding coupled inductors are $2.3,1.5$, and $0.76 \mathrm{~A}$ peaks as calculated in (66). From the waveforms in Figure 22, using a
TABLE 3: Total harmonic distortion under different solar radiation conditions.

\begin{tabular}{lcccc}
\hline \multirow{2}{*}{ Solar radiation } & \multicolumn{2}{c}{ THD (\%) } & \multicolumn{2}{c}{ Fundamental value } \\
& Voltage & Current & Voltage $(\mathrm{V})$ & Current $(\mathrm{A})$ \\
\hline $1000\left(\mathrm{~W} / \mathrm{m}^{2}\right)$ & 13.64 & 0.68 & 184.0 & 8.80 \\
$600\left(\mathrm{~W} / \mathrm{m}^{2}\right)$ & 13.65 & 1.15 & 181.8 & 5.20 \\
$400\left(\mathrm{~W} / \mathrm{m}^{2}\right)$ & 12.78 & 2.80 & 180.9 & 3.44 \\
$0\left(\mathrm{~W} / \mathrm{m}^{2}\right)$ & 23.94 & 0.35 & 148.3 & 9.98 \\
\hline
\end{tabular}

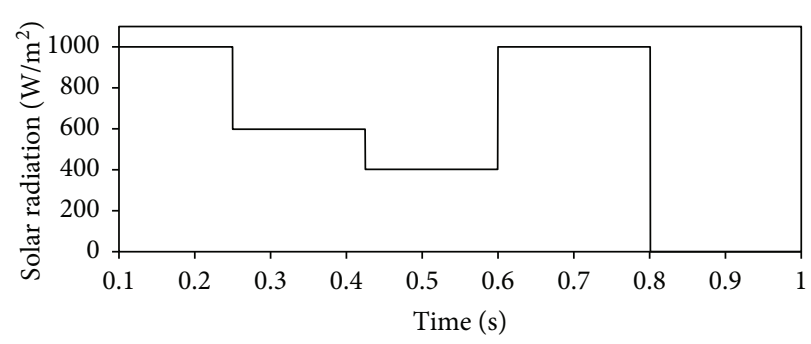

FIGURE 27: Step changes in solar radiation.

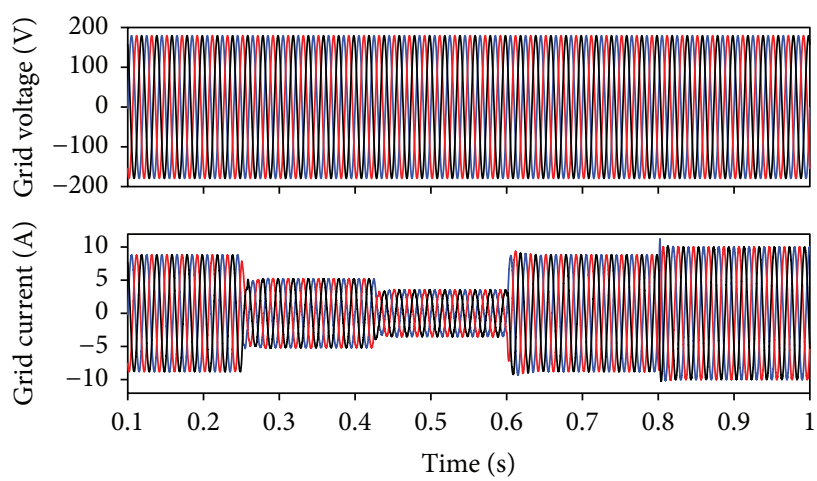

FIGURE 28: Response to changes in solar irradiance in the hexagram converter.

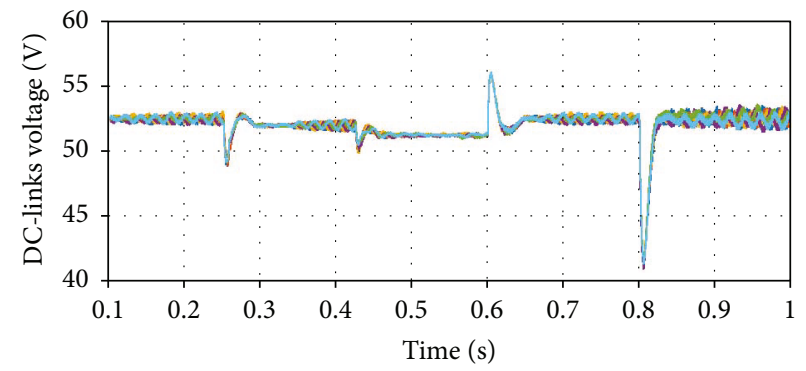

FIgURE 29: Variations in DC-link voltages in response to the changes in solar radiation.

six-winding coupled inductor, the circulating current is efficiently minimized.

In order to achieve the same circulating currents (e.g., $0.5 \mathrm{~A}$ ), the magnetizing inductance of the two-winding, three-winding and six-winding coupled inductors should be 


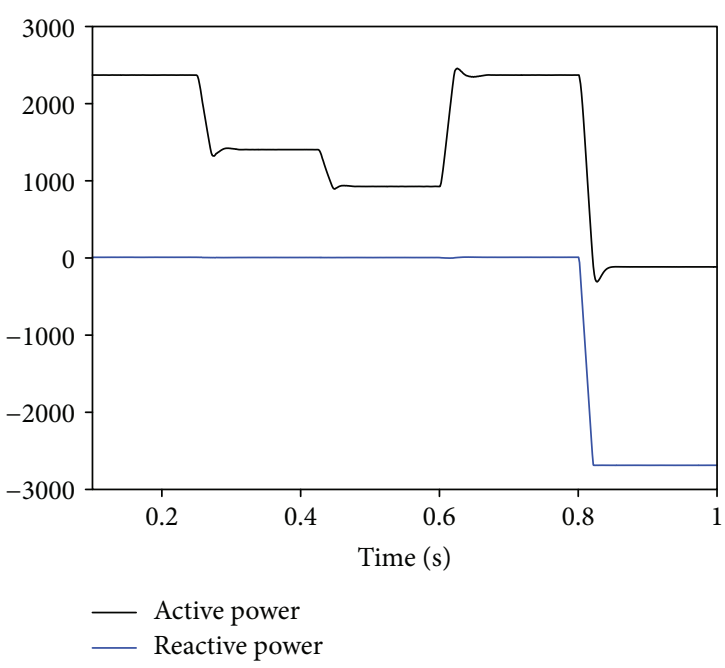

(a)

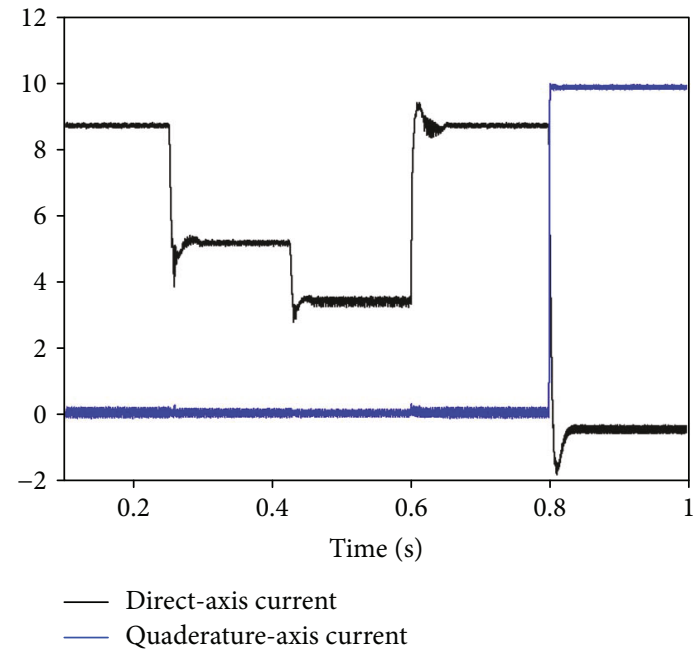

(b)

FIgURE 30: Response to changes in solar radiation. (a) Output active and reactive power, and (b) direct and quadrature axis current.

increased to $17.5,11.6$, and $6 \mathrm{mH}$, respectively. As shown in Figure 23, the waveform matches the theoretical analysis in Figure 21. The output current of module 1, module 3, and the circulating current inside the HMC with two-winding, three-winding, and six-winding coupled inductors under an unbalanced DC link voltage are shown in Figures 24, 25, and 26, respectively. The waveforms show the simulation result with an extremely small magnetizing inductance of $0.5 \mathrm{mH}$, which is $1 / 7$ of that in Figure 22. The simulations validated the quantitative relationship that the circulating current will be too big to maintain a normal operation if the coupled inductors with low magnetizing inductance are used. As shown, the current ia3 nearly doubles the circulating current, which evidently proves that the HMC is sensitive to an unbalanced DC voltage. The waveforms match the theoretical analysis in Figure 21.

6.2. Active Power Variation. The system is tested for different solar radiation conditions and the results are shown in Table 3. Figure 27 shows the solar radiation variation which is considered in this study. The output current and grid voltage variation in response to the changes in solar radiation is shown in Figure 28. The transient behavior of the total DC-link voltage is presented in Figure 29. The parameters are successfully attuned by the controller to keep the DC-link voltage at the desired level of 52.6 V. Fluctuations are observed in the DC-links, due to the step variations in the solar radiation. Nevertheless, the controller brings the voltage to the reference level within $0.02 \mathrm{~s}$.

The active power supplied by the HMC is directly proportional to the magnitude of direct axis, $i_{\mathrm{d}}$, as indicated by (38). The solar radiation at all DC links is reduced by $40 \%$ at $0.25 \mathrm{~s}$. The fluctuation in solar radiation is imitated through the reduction in the direct-axis current by approximately $40 \%$, in a step. It decreased to $5.216 \mathrm{~A}$ from the initial value of $8.823 \mathrm{~A}$, as shown in Figure 30 . This reduction in $i_{\mathrm{d}}$ was to keep the DC-link voltage at the reference level by decreasing the output power drawn from the PV. Moreover, to guarantee maximum utilization of the PV system, the quadrature axis current was kept at zero. At $0.45 \mathrm{~s}$, the solar radiation is further reduced to $400 \mathrm{~W} / \mathrm{m}^{2}$. The direct-axis current is reduced to $3.267 \mathrm{~A}$ from the original value of 5.216 A. Later, the direct-axis current is increased to $8.823 \mathrm{~A}$, because of the increment in the solar radiation.

6.3. Reactive Power Compensation. The described control algorithm permits the HMC to act as DSTATCOM in the absence of solar radiation. The output reactive power can be calculated as

$$
Q_{\text {out }}=-\frac{3}{2} I_{q} V_{d}
$$

In this condition, the reactive power is increased by $2700 \mathrm{VAR}$ in a step, in the absence of solar radiation. The influence, for the DSTATCOM mode operation, is presented in Figure 31.

The direct-axis current is found to be zero, indicating the fact that no active power is being transferred to the grid in the absence of solar radiation. However, due to the step change in reactive power, the capacitors consume current from the grid. It is found that the direct-axis current takes $0.02 \mathrm{~s}$ to stabilize. The nature of the fluctuation in the DC-link voltage is depicted in Figure 29. The DC-link controller effectively keeps the DC-link voltage by regulating the power flow through the capacitor. Hence, it can be mentioned that the HMC effectively operates as DSTATCOM in the absence of solar radiation. Figure 31 shows the source voltage and converter output current in DSTATCOM mode. The waveforms show that the output current increases after the reactive power command comes at $0.8 \mathrm{~s}$. Moreover, Figure 31 approves that the phase difference of the converter output current with grid voltage is $90^{\circ}$ in this mode of operation. 


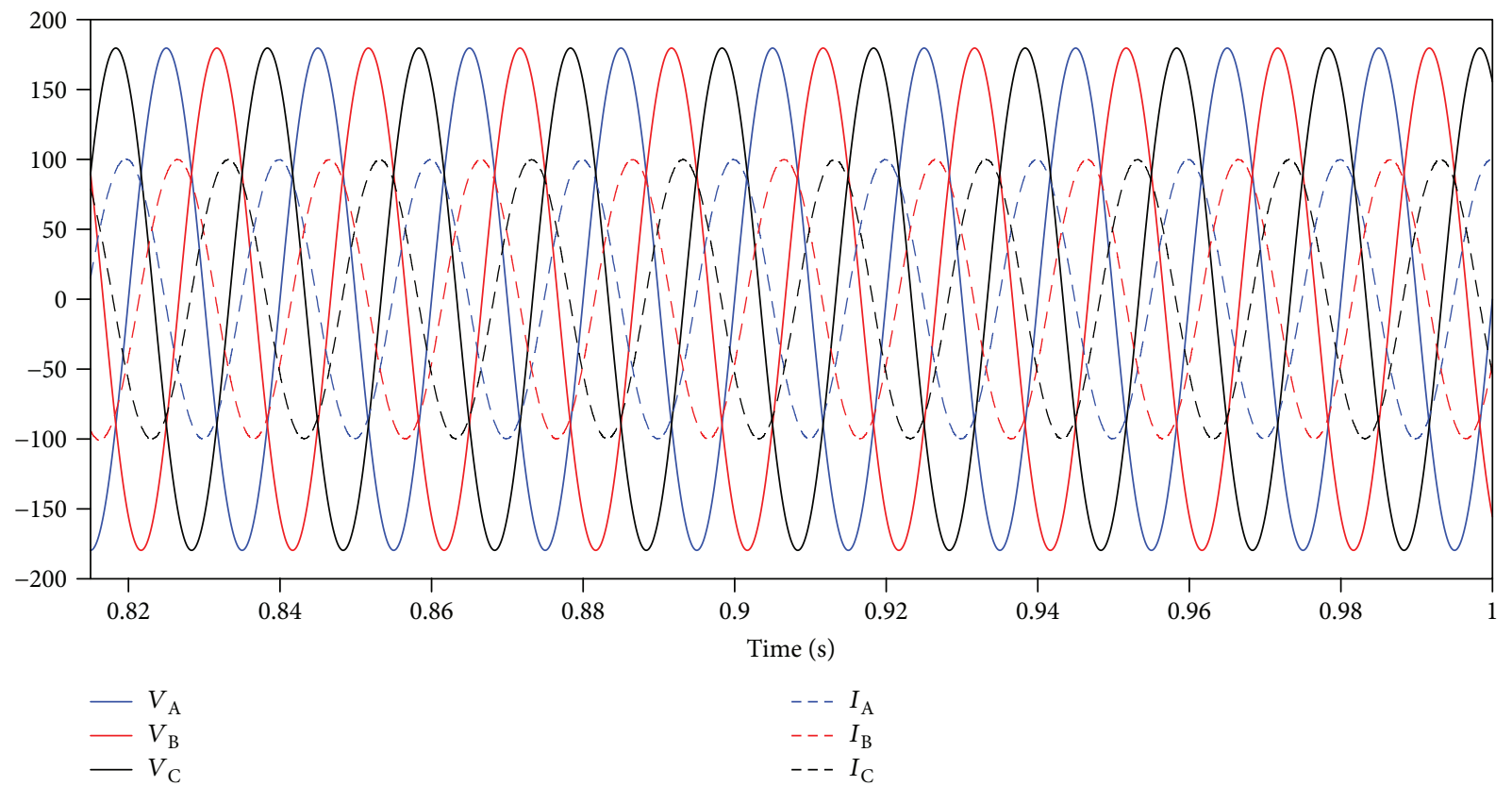

FIGURE 31: System performance with the increase in the reactive power supply in DSTATCOM mode.

\section{Conclusion}

The HMC for a grid-connected PV system shares many advantages of the $\mathrm{CHB}$ but uses fewer switches and reduces the size of the DC-link capacitor. However, the HMC is sensitive to the loop voltage produced by the probable DC-link voltage unbalance. The unbalanced conditions of the DC-link voltages will initiate a linefrequency circulating current. Therefore, to minimize the circulating current as well as to reduce an extra voltage drop on the inductors that affects the terminal voltage, the inductance value should be adequate. The multiwinding coupled inductors are the key to control the circulating current and ensure the proper operation of the HMC. The equivalent circuit model of the HMC configuration is derived to recognize the control scheme. The two-winding coupled inductor imposes twelve times the magnetizing inductance for the circulating current, while the impedance to the circulating current using threewinding coupled inductors is eighteen times as much as the magnetizing inductance. Owing to the six-winding coupled inductor, the impedance on the circulating current path is thirty-six times the magnetizing inductance. The results show the good performance of the control algorithm in both steady state and transient conditions. Moreover, it is interesting to note that in the absence of solar radiation, the controller acts in DSTATCOM mode to supply reactive power to the grid. The performance of the controller under different solar radiation conditions is found to be satisfactory.

\section{Conflicts of Interest}

The authors declare that they have no conflicts of interest.

\section{Acknowledgments}

The authors would like to express their thanks to King Abdulaziz City for Science and Technology (KACST) for providing financial and technical support to this study.

\section{References}

[1] Z. M. Shahrbabak, A. Tabesh, and G. R. Yousefi, "Economical design of utility-scale photovoltaic power plants with optimum availability," IEEE Transactions on Industrial Electronics, vol. 61, no. 7, pp. 3399-3406, 2014.

[2] A. A. Al-Shamma'a and K. E. Addoweesh, "Techno-economic optimization of hybrid power system using genetic algorithm," International Journal of Energy Research, vol. 38, no. 12, pp. 1608-1623, 2014.

[3] J. H. R. Enslin and P. J. M. Heskes, "Harmonic interaction between a large number of distributed power inverters and the distribution network," IEEE Transactions on Power Electronics, vol. 19, no. 6, pp. 1586-1593, 2004.

[4] Y. Riffonneau, S. Bacha, F. Barruel, and S. Ploix, "Optimal power flow management for grid connected PV systems with batteries," IEEE Transactions on Sustainable Energy, vol. 2, no. 3, pp. 309-320, 2011.

[5] P. G. Arul, V. K. Ramachandaramurthy, and R. K. Rajkumar, "Control strategies for a hybrid renewable energy system: a review," Renewable and Sustainable Energy Reviews, vol. 42, pp. 597-608, 2015.

[6] J. M. Guerrero, P. C. Loh, T.-L. Lee, and M. Chandorkar, "Advanced control architectures for intelligent microgrids-part II: power quality, energy storage, and AC/DC microgrids," IEEE Transactions on Industrial Electronics, vol. 60, no. 4, pp. 1263-1270, 2013.

[7] M. A. Elsaharty, H. A. Ashour, E. Rakhshani, E. Pouresmaeil, and J. P. S. Catalao, "A novel DC-bus sensor-less MPPT 
technique for single-stage PV grid-connected inverters," Energies, vol. 9, no. 4, pp. 1-23, 2016.

[8] J. Rodriguez, J. S. Lai, and F. Z. Peng, "Multilevel inverters: a survey of topologies, controls, and applications," IEEE Transactions on Industrial Electronics, vol. 49, no. 4, pp. 724-738, 2002.

[9] J. A. Barrena, L. Marroyo, M. Á. Rodriguez Vidal, and J. R. T. Apraiz, "Individual voltage balancing strategy for PWM cascaded H-bridge converter-based STATCOM," IEEE Transactions on Industrial Electronics, vol. 55, no. 1, pp. 21-29, 2008.

[10] K. K. Gupta, A. Ranjan, P. Bhatnagar, L. K. Sahu, and S. Jain, "Multilevel inverter topologies with reduced device count: a review," IEEE Transactions on Power Electronics, vol. 31, no. 1, pp. 135-151, 2016.

[11] L. Franquelo, J. Rodriguez, J. Leon, S. Kouro, R. Portillo, and M. Prats, "The age of multilevel converters arrives," IEEE Industrial Electronics Magazine, vol. 2, no. 2, pp. 28-39, 2008.

[12] A. Nabae, I. Takahashi, and H. Akagi, "A new neutral-pointclamped PWM inverter," IEEE Transactions on Industry Applications, vol. IA-17, no. 5, pp. 518-523, 1981.

[13] M. F. Escalante, J. C. Vannier, and A. Arzandé, "Flying capacitor multilevel inverters and DTC motor drive applications," IEEE Transactions on Industrial Electronics, vol. 49, no. 4, pp. 809-815, 2002.

[14] M. A. Pérez, S. Bernet, J. Rodriguez, S. Kouro, and R. Lizana, "Circuit topologies, modeling, control schemes, and applications of modular multilevel converters," IEEE Transactions on Power Electronics, vol. 30, no. 1, pp. 4-17, 2015.

[15] Y. Yu, G. Konstantinou, B. Hredzak, and V. G. Agelidis, "Power balance of cascaded $\mathrm{H}$-bridge multilevel converters for large-scale photovoltaic integration," IEEE Transactions on Power Electronics, vol. 31, no. 1, pp. 292-303, 2016.

[16] E. Cengelci, P. Enjeti, C. Singh, F. Blaabjerg, and J. K. Pederson, "New medium voltage PWM inverter topologies for adjustable speed AC motor drive systems," in APEC '98. Conference Proceedings 1998, Thirteenth Annual Applied Power Electronics Conference and Exposition, pp. 565-571, Anaheim, CA, USA, 1998.

[17] R. Teodorescu, F. Blaabjerg, J. K. Pedersen, E. Cengelci, and P. N. Enjeti, "Multilevel inverter by cascading industrial VSI," IEEE Transactions on Industrial Electronics, vol. 49, no. 4, pp. 832-838, 2002.

[18] J. Wen and K. Ma Smedley, "Hexagram inverter for mediumvoltage six-phase variable-speed drives," IEEE Transactions on Industrial Electronics, vol. 55, no. 6, pp. 2473-2481, 2008.

[19] J. Wen and K. M. Smedley, "Synthesis of multilevel converters based on single- and/or three-phase converter building blocks," IEEE Transactions on Power Electronics, vol. 23, no. 3, pp. 1247-1256, 2008.

[20] M. G. Vaillalva, J. R. Gazoli, and E. R. Filho, "Comprehensive approach to modeling and simulation of photovoltaic arrays," IEEE Transactions on Power Electronics, vol. 24, no. 5, pp. 1198-1208, 2009.

[21] L. Piegari, R. Rizzo, I. Spina, and P. Tricoli, "Optimized adaptive perturb and observe maximum power point tracking control for photovoltaic generation," Energies, vol. 8, no. 5, pp. 3418-3436, 2015.

[22] J. A. Barrena, L. Marroyo, M. A. R. Vidal, and J. R. T. Apraiz, "Individual voltage balancing strategy for PWM cascaded H-bridge converter-based STATCOM," IEEE Transactions on Industrial Electronics, vol. 55, no. 1, pp. 21-29, 2008.
[23] S. Debnath, J. Qin, B. Bahrani, M. Saeedifard, and P. Barbosa, "Operation, control, and applications of the modular multilevel converter: a review," IEEE Transactions on Power Electronics, vol. 30, no. 1, pp. 37-53, 2015.

[24] M. Moranchel, F. Huerta, I. Sanz, E. Bueno, and F. Rodríguez, "A comparison of modulation techniques for modular multilevel converters," Energies, vol. 9, no. 12, pp. 1-20, 2016.

[25] D. Holmes and T. Lipo, Pulse width modulation for power converters, IEEE Press, Piscataway, NJ, USA, 2003. 

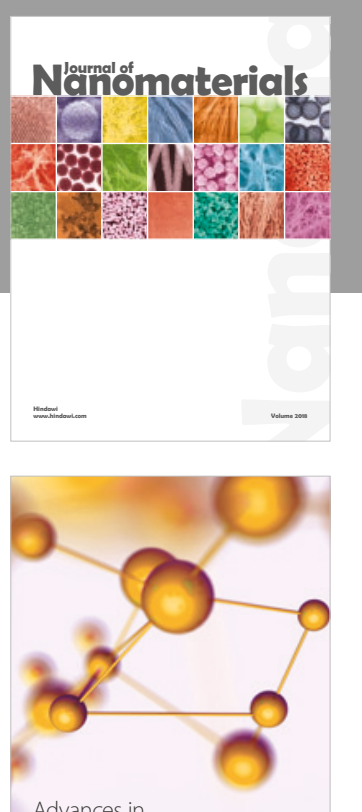

Physical Chemistry
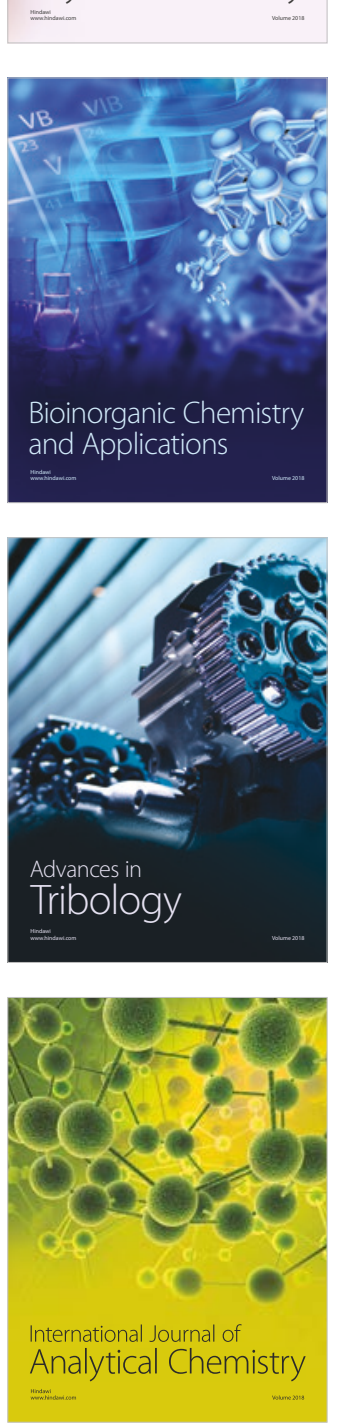

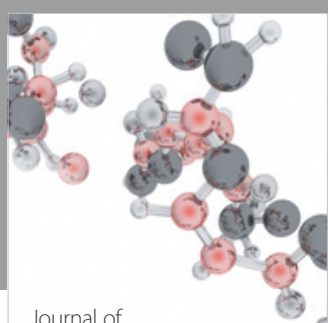

Analytical Methods

in Chemistry

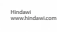

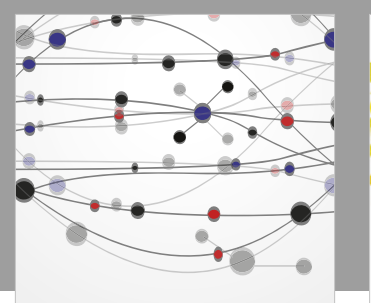

The Scientific World Journal

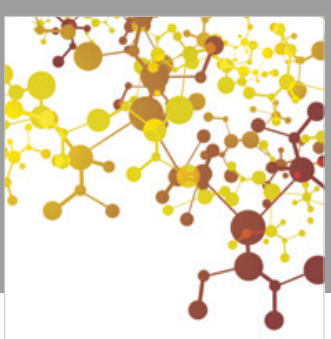

Journal of

Applied Chemistry
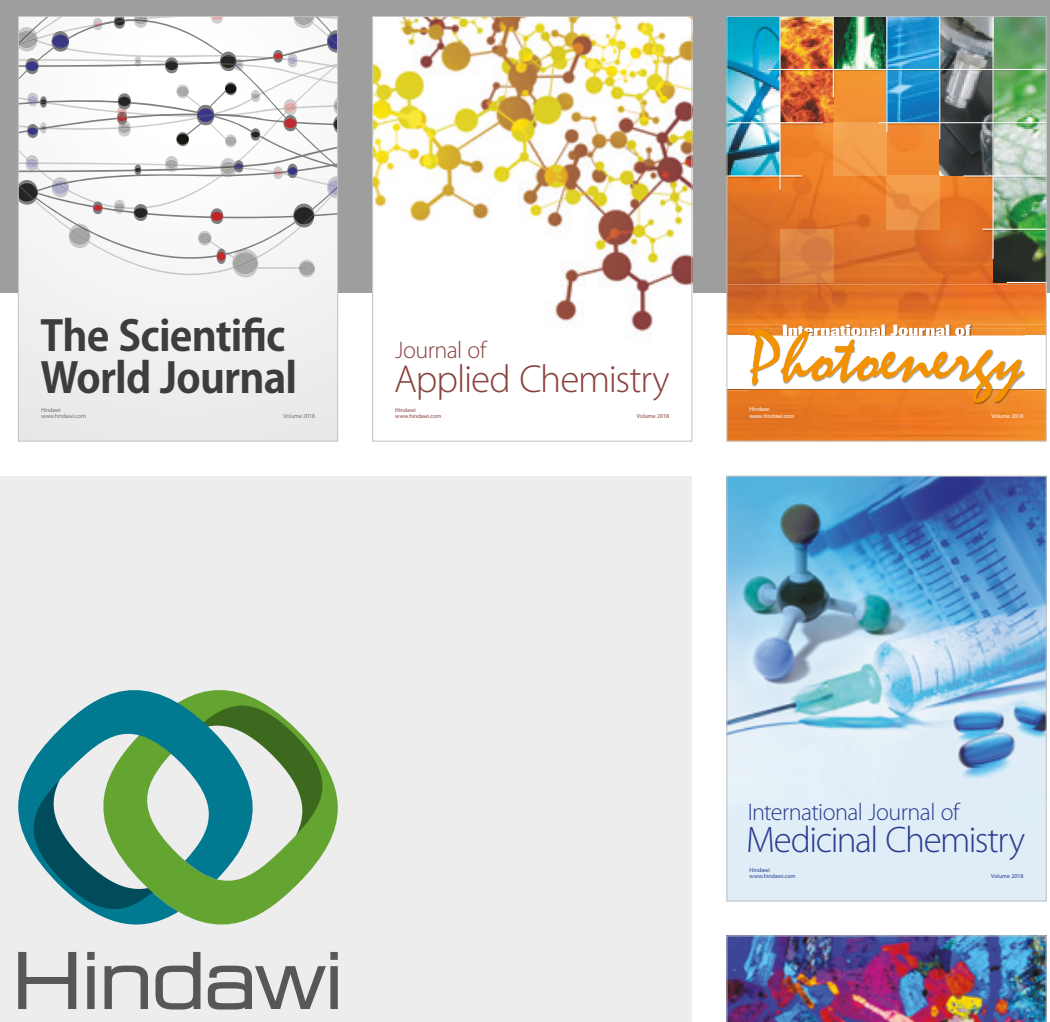

Submit your manuscripts at

www.hindawi.com
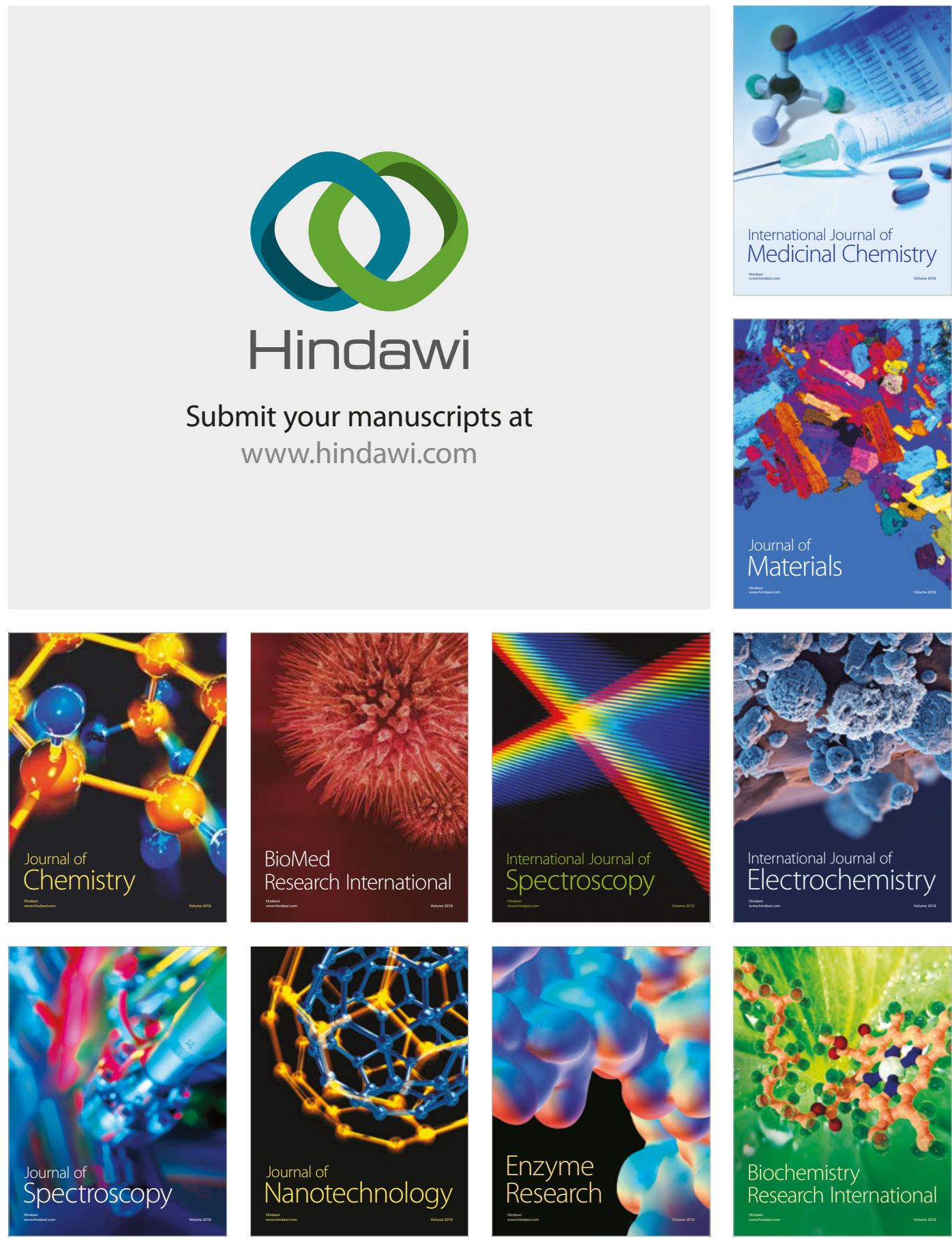
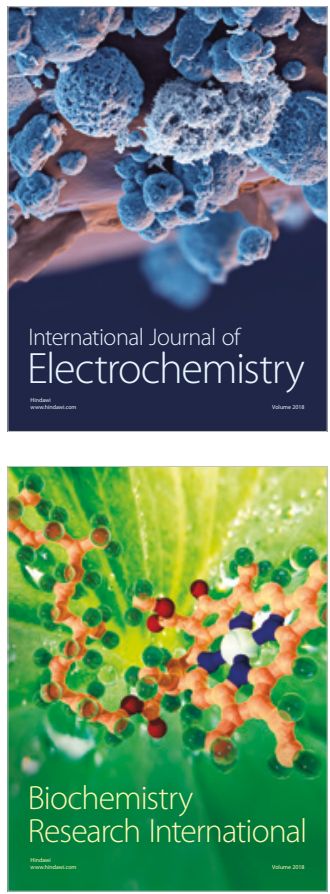